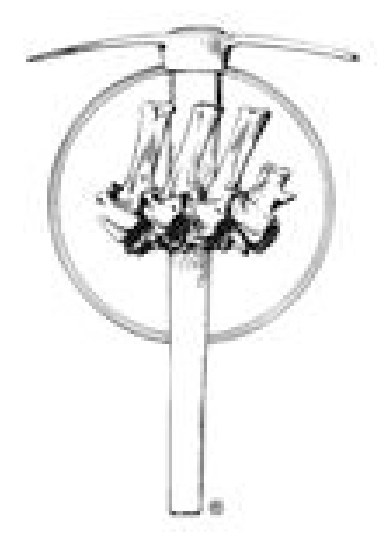

Lepidotes gloriae, sp, nov. (Actinopterygii: Semionotiformes) from the Late Jurassic of Cuba Author(s): Detlev Thies

Source: Journal of Vertebrate Paleontology, Vol. 9, No. 1 (Mar. 30, 1989), pp. 18-40

Published by: The Society of Vertebrate Paleontology

Stable URL: http://www.jstor.org/stable/4523235

Accessed: 16/04/2009 16:50

Your use of the JSTOR archive indicates your acceptance of JSTOR's Terms and Conditions of Use, available at http://www.jstor.org/page/info/about/policies/terms.jsp. JSTOR's Terms and Conditions of Use provides, in part, that unless you have obtained prior permission, you may not download an entire issue of a journal or multiple copies of articles, and you may use content in the JSTOR archive only for your personal, non-commercial use.

Please contact the publisher regarding any further use of this work. Publisher contact information may be obtained at http://www.jstor.org/action/showPublisher?publisherCode=vertpaleo.

Each copy of any part of a JSTOR transmission must contain the same copyright notice that appears on the screen or printed page of such transmission.

JSTOR is a not-for-profit organization founded in 1995 to build trusted digital archives for scholarship. We work with the scholarly community to preserve their work and the materials they rely upon, and to build a common research platform that promotes the discovery and use of these resources. For more information about JSTOR, please contact support@jstor.org.

The Society of Vertebrate Paleontology is collaborating with JSTOR to digitize, preserve and extend access to Journal of Vertebrate Paleontology. 


\title{
LEPIDOTES GLORIAE, SP. NOV. (ACTINOPTERYGII: SEMIONOTIFORMES) FROM THE LATE JURASSIC OF CUBA
}

\author{
DETLEV THIES \\ Museum of Natural History, The University of Kansas, Lawrence, Kansas 66045-2454 \\ (Present address: Institut für Geologie und Paläontologie, Universität Hannover, \\ Callinstraße 30, D-3000 Hannover 1, West Germany)
}

\begin{abstract}
Lepidotes gloriae, sp. nov. (Actinopterygii: Semionotiformes) from the Late Jurassic of Western Cuba is described. The skeletal anatomy of this fish shows two features previously unknown in Lepidotes Agassiz, 1832: 1) presence of two pairs of ectopterygoids and 2) presence of dermometapterygoids. Skeletal elements whose structure is little known or even unknown in other species of Lepidotes have been studied in detail in L. gloriae: 1) branchial tooth plates, 2) endoskeletal shoulder girdle, 3) posttemporal, 4) clavicle, 5) pelvic girdle, and 6) caudal fin skeleton. The sensory canal system on the head of $L$. gloriae is unique among other species of Lepidotes in having the median part of the supratemporal commissure enclosed within the parietals, in having a medio-anteriorly directed branch of the infraorbital canal behind the orbit reaching from the dermopterotic into the frontal, and in having the ventral part of the median pit line of the skull roof replaced by a short canal traversing the dermopterotic. The cranial sensory canal system is unique among actinopterygians in having developed an oral canal dorsal to the mandibular canal in the anterior part of the dentalosplenial.
\end{abstract}

\section{INTRODUCTION}

The Late Jurassic of Western Cuba although as yet incompletely studied is rich in fossil fishes at some localities and horizons. This is especially true of the Upper Jurassic outcrops in the Viñales Basin (Province Piñar del Rio). It is therefore no surprise that this region has been of interest to geologists and paleontologists since the beginning of this century. Their activities are reflected in part in the formation of large collections of Cuban Late Jurassic fossils that today are deposited in the Museo Poey (University of Habana, Cuba) and in several museums in the United States (e.g., Museum of Comparative Zoology, Harvard University; American Museum of Natural History, New York; National Museum of Natural History, Smithsonian Institution, Washington, D.C.). However, despite the abundance of material only a few genera of the actinopterygian fauna from the Late Jurassic of Cuba have been studied so far: Gyrodus, $\mathrm{Ca}$ turus, Sauropsis?, Eugnathides, Leptolepis?, and Luisichthys (Gregory, 1923; White, 1942; Arratia and Schultze, 1985).

Some years ago while studying Late Jurassic teleosteans from Chile and Cuba G. Arratia and H.-P. Schultze examined the Cuban material in the National Museum of Natural History (USNM). Within this material they accidentally discovered some Lepidotes remains and drew my attention to it. The genus Lepidotes Agassiz, 1832 represents a Mesozoic actinopterygian taxon rich in species that ranges from the Triassic into the Late Cretaceous. The genus had an almost worldwide distribution, however the majority of species were described from the Jurassic and Cretaceous of Europe
(Woodward, 1895; Schaeffer and Patterson, 1984). Outside Europe Jurassic specimens of Lepidotes have been reported from Africa, Asia (especially India), and from North, Central, and South America (Schaeffer and Patterson, 1984). Of these only the European and Indian records have been adequately studied (Woodward, 1895; Jain and Robinson, 1963; Jain, 1983) leaving the material from the Jurassic of the Americas thus far only insufficiently described. In this light a detailed description of the Late Jurassic Cuban Lepidotes material from the USNM is desirable. This material shows many anatomical details previously unknown in Lepidotes.

\section{ABBREVIATIONS}

Morphology - asc. proc. Pmx, ascending process of premaxilla; Ao, antorbital; Boc, basioccipital; b. proc, basipterygoid process; $\mathbf{C h}$, ceratohyal; $\mathbf{C l}$, cleithrum; Cla, clavicle; cll, canal for cephalic portion of lateral line; Co, coronoid; Dmtp, dermometapterygoid; Dpal $\mathbf{1}, \mathbf{2}$, dermopalatines 1 and 2; d. proc. $\mathbf{C l}$, dorsal process of cleithrum; Dspl, dentalosplenial; E, epural; ec, canal for ethmoidal commissure; Ectp 1, 2, ectopterygoids 1 and 2; Entp, entopterygoid; Epi, epiotic; Exo, exoccipital; Fr, frontal; fri, facet for articulation of a cranial rib; g.s.o, groove for superficial ophthalmic nerves; H 1-7, hypurals 1-7; Har (Pu 1-6), haemal arches and spines of first six preural vertebrae; Hym, hyomandibula; Io, infraorbital; ioc, infraorbital canal; Iop, interoperculum; jc, jugular canal; lcc, lateral cranial canal; lco, lateral commissure; Le, lepidotrichia; mbioc, medioanteriorly directed branch of infraor- 
bital canal; mc, mandibular canal; mpl, median pit line of skull roof; $\mathbf{m}$. proc. Mx, median process of maxilla; Mtp, metapterygoid; Mx, maxilla; myo, posterior myodom; Na, nasal; Nar, neural arches of preural vertebrae; oc, oral canal; oca, foramen for occipital artery; ocn, foramina for roots of occipital nerves; Op, operculum; op. proc. Hym, opercular process of hyomandibula; Pa, parietal; Pcl, postcleithrum; Pmx, premaxilla; pP, pelvic plate; Pro, prootic; prof, foramen for profundus nerve; Ps, parasphenoid; psa, notch for efferent pseudobranchial artery; psc, groove for posterior semicircular canal; Pt, posttemporal; Ra, radials; $\mathbf{R b}$, branchiostegal rays; $\mathbf{r}$. mand. lat, foramina for terminal branches of ramus mandibularis lateralis; $\mathbf{r}$. ot. lat, foramina and canal for otic branch of lateralis nerve; r. pal. VII, foramina or groove for palatine nerve; rr. hym. VII + mand. lat, joint foramen for hyomandibular branch of facial nerve and mandibular branch of lateralis nerve; Sc, scales; Scl, supracleithrum; Sco, scapulocoracoid; Smx, supramaxilla; Sp, spine of pectoral fin; spic, spiracular canal; Spo, sphenotic; soc, supraorbital canal; Sop, suboperculum; st, supratemporal commissure; sup, posterior pocket in epiotic; tfc, trigeminofacial chamber; Vo, vomer; v. proc. Pt, ventral process of posttemporal; $\mathbf{I}$, canal and openings for olfactory nerve; III, foramen for oculomotor nerve; $\mathbf{V}$, foramen for trigeminal nerve; $\mathbf{X}$, foramen for vagus nerve; (a), anterior; (p), posterior; (l), left; (r), right.

Institutions-BMNH, British Museum (Natural History); KU, Museum of Natural History, The University of Kansas; USNM, National Museum of Natural History (Smithsonian Institution).

\section{MATERIAL AND METHODS}

The Lepidotes material from the Late Jurassic of Cuba deposited in the USNM comprises four specimens:

USNM 18611-fragment of a squamation in part and counterpart. Locality: Hoyo de San Antonio, Province of Piñar del Rio, Western Cuba. Age: Oxfordian (Jagua-limestone).

USNM 18612-posterior part of the skull and part of the squamation in part and counterpart; fragment of the squamation in 14 pieces. Locality: Hoyo de San Antonio, Province of Piñar del Rio, Western Cuba. Age: Oxfordian (Jagua-limestone).

USNM 21608-caudal fin in part and counterpart. Locality: Hoyo de San Antonio (5,720 m east of road junction north of San Vicente), Province of Piñar del Rio, Western Cuba. Age: Oxfordian (Jagua-limestone).

USNM 279856-nearly complete specimen in part and counterpart (five slabs). Locality: Western Cuba. Age: Late Jurassic. (Specific locality and age of this specimen unknown, but probably the same as in the other specimens.)

In regard to their stratigraphic provenance the specimens are labelled as being from the "Jagua-limestone." The exact stratigraphical position of this limestone is unclear. It is probably identical with the Jagua
Vieja Member of the Jagua Formation (Oxfordian) (Herrera, 1961; Wierzbowski, 1976).

From the above listed (unprepared) material only USNM 279856 was selected for preparation. The part and the skull portion of the counterpart of the specimen were prepared by applying the transfer technique (Toombs and Rixon, 1950). The specimen was dusted with ammonium chloride $\left(\mathrm{NH}_{4} \mathrm{Cl}\right)$ before photographing.

\section{SYSTEMATIC PALEONTOLOGY}

Division Halecostomi Regan, 1923

Order SEMIONOTIFORMES Arambourg and Bertin, 1958

Family SEMIONOTIDAE Lehman, 1966

(=SEMIONOTIDAE Woodward, 1890 partim)

\section{LEPIDOTES Agassiz, 1832}

Synonymy - See Woodward (1895:77).

Revised Diagnosis-Fusiform semionotids with an unpaired or coossified vomer in the adults. More than one suborbital present on the cheek. Dentalosplenial with a long posterior process reaching or almost reaching the posterior border of the mandible. Two pockets present in the epiotic. Dorsal ridge scales inconspicuous, without a posterior spine.

Discussion-All previous attempts to characterize the genus Lepidotes are insufficient (Woodward, 1895, 1916-1919; Jain, 1983; for a critical review of Jain's revised diagnosis see McCune, 1986). Among the characters listed by previous authors only the structure of the vomer is useful in separating Lepidotes from the allied fusiform semionotids Acentrophorus and Semionotus. Whereas the vomer is unpaired in Lepidotes this ossification is paired in Acentrophorus and Semionotus (Gill, 1923; Schaeffer and Dunkle, 1950; Patterson, 1973). But even this character may fail to characterize juvenile specimens of Lepidotes. Jain (1983) stated that in smaller specimens of $L$. deccanensis the vomer is paired and that it becomes coossified only in larger individuals. Among semionotids a median vomer also occurs in the hypsisomatic genera Dapedium and Tetragonolepis (Patterson, 1973; Thies, in prep.).

More than one suborbital is present on a side in Lepidotes and Acentrophorus (Gill, 1923; Gardiner, 1960). In contrast, Semionotus has only one cheek plate (McCune, 1986, 1987). On the basis of this character McCune (1986:227) regarded Lepidotes minor as a Semionotus stating that " $L$. minor Agassiz is figured by Woodward (1916-1919: fig. 14) as having only one suborbital, although earlier Woodward (1895) figured L. minor as having several suborbitals." This is incorrect. In his figure 14 Woodward (1916) drew $L$. minor with two suborbitals. McCune (1986:227) also claimed that "other species of Lepidotes, such as $L$. toombsi (BMNH P25180) in which the metapterygoid or other elements of the palate have been mistaken for dermal cheek plates (Jain and Robinson 1963), should probably also be referred to Semionotus...." This seems to be incorrect as well. The figures and careful 
description of L. toombsi given by Jain and Robinson (1963) leave no doubt that the authors correctly identified the metapterygoid and other palatal elements as well as the cheek plates in BMNH P25180 and that $L$. toombsi possesses more than one suborbital. For these reasons I do not agree with McCune (1986) and still consider $L$. minor and L. toombsi to be species of Lepidotes. Further characters suggested by McCune (1986) to distinguish Lepidotes from Semionotus are body size with Lepidotes being generally larger than Semionotus and the dentition, which is of crushing type in Lepidotes and unspecialized in Semionotus. The first criterion (body size) is of little diagnostic value. It is not applicable in juvenile specimens and the maximum body size is difficult to assess in fishes because these animals grow continuously throughout life. Against the second criterion (dentition) I must object that there are at least two species of Lepidotes with a non-tritoral dentition among which is $L$. elvensis, the type species of Lepidotes (Jain, 1983).

A dentalosplenial with a long posterior process reaching the posterior border of the mandible is present in some species of Lepidotes (e.g., L. elvensis, L. lennieri, L. maximus; Wenz, 1967; Jain, 1983). In $L$. toombsi and $L$. roxo $i$ this process almost reaches the posterior margin of the mandible (Silva Santos, 1953; Jain and Robinson, 1963). In other species the process remains much shorter (e.g., L. laevis, L. notopterus; Saint-Seine, 1949). In Acentrophorus and Semionotus the dentalosplenial never extends posteriad to the hinder margin of the lower jaw (Gill, 1923; Schaeffer and Dunkle, 1950; Gardiner, 1960; Larsonneur, 1964; McCune, 1986).

The formation of two pockets in the epiotic possibly represents a constant character in Lepidotes. Its presence, however, is as yet demonstrated only for $L$. toombsi, other species of Lepidotes being insufficiently studied. Patterson (1975) suspected the existence of the second (posterior) pocket in the epiotic is a primitive feature. Little information is available on the braincases of Acentrophorus and Semionotus and nothing is known about the structure of the epiotic in these fishes.

With regard to the morphology of dorsal ridge scales, McCune (1986:218, 1987:30) stated that "Semionotus . . . shares with most Lepidotes a series of simple, convex scales with moderate to well developed, posteriorly directed spines along the dorsal midline between the extrascapulars and the origin of the dorsal fin." I am not sure if this is correct. Spined dorsal ridge scales do have a wide distribution among species of Semionotus (e.g., S. bergeri, S. kapffi, S. normanniae; McCune, 1986, 1987). But in Lepidotes, a genus containing about 40 species, the only species with similar dorsal ridge scales as found in $S$. bergeri (type species of Semionotus) that I could trace with certainty from published records are $L$. minor, $L$. maximus, and $L$. mantelli (Woodward, 1895, 1916; Weitzel, 1930). (McCune, 1987 also mentioned $L$. laevis and L. toombsi.) In other species of Lepidotes, including the type species, $L$. el- vensis (Quenstedt, 1847; Wenz, 1967), the dorsal ridge scales are inconspicuous, i.e., more or less pointed posteriorly but without a posterior spine.

In summary, the diagnostic characters of Lepidotes listed above are either primitive or not present in all members of the genus. But in combination they may be useful for the generic identification of specimens of Lepidotes in the traditional (non-cladistic) sense of the genus. I was unable to identify a single autapomorphy of Lepidotes within the bulk of anatomical data already published on this genus. This does not mean that there is no such autapomorphy. However, at the present state of knowledge of the genus and considering its high number of species and its long stratigraphic range (Late Triassic to Late Cretaceous) I tend to consider Lepidotes as a paraphyletic or polyphyletic taxon. I agree with McCune (1986) in that a revision of the genus Lepidotes is needed but this is beyond the scope of the present study.

Type Species-Lepidotes elvensis (Blainville, 1818) from the Upper Lias of France, Germany, and England.

\section{LEPIDOTES GLORIAE, sp. nov.}

Holotype-USNM 279856-nearly complete specimen in part and counterpart from the Late Jurassic of Western Cuba.

Questionably Referred Specimens-USNM 21608, USNM 18611; both from the Late Jurassic (Oxfordian) of Western Cuba.

Etymology-Named in honor of Professor Gloria Arratia.

Diagnosis - Dermal skull roofing bones without ganoin cover. Dermal bones of skull and shoulder girdle smooth (a few rudimentary tubercles may be present). Frontal at least three times as long as parietal. Left and right parietal of almost equal size. In adults operculum nearly twice as high as broad. Anterior and posterior pit line of skull roof lacking; middle pit line reduced and replaced by short canal, which is incorporated into dermopterotic. Supratemporal commissure crosses posterior part of parietal. Oral canal present in anterior part of dentalosplenial. Teeth conical and pointed, nontritoral. Pectoral and pelvic fins without fulcra, pectoral fin with spine. Anterior flank scales smooth, slightly less than twice as high as long and covered by ganoin; posterior border serrated over its entire length.

Lepidotes gloriae differs from all other Late Jurassic species of Lepidotes by the following combination of characters: dermal bones of skull and shoulder girdle smooth, dentition non-tritoral, pectoral and pelvic fins without fulcra, pectoral fin with spine, and posterior border of anterior flank scales serrated over its entire length.

Remark-Based on its cranial anatomy, scale morphology, and size USNM 18612 may also belong to the genus Lepidotes. It differs, however, from USNM 279856 in that its operculum and preserved skull roofing bones bear an ornament of elongated strong rugae. 


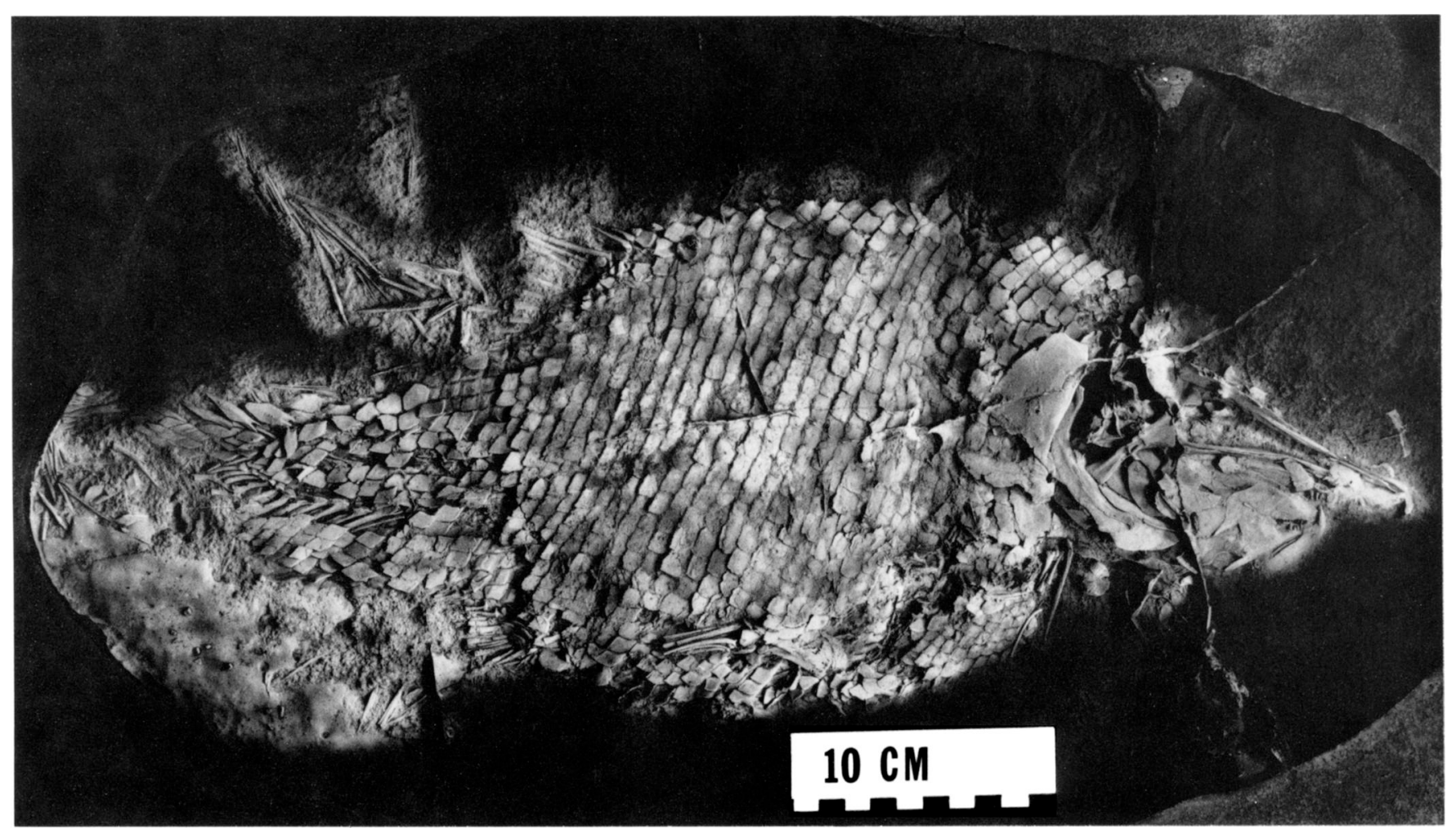

FIGURE 1. Lepidotes gloriae, sp. nov. (holotype, USNM 279856, part).

The remains are not sufficient for a proper specific identification.

\section{DESCRIPTION}

The description of the new species is exclusively based on the holotype (USNM 279856, Fig. 1). Because of the extensive ossification in the endochondral neurocranium the holotype probably represents an adult individual. The preserved parts (skull, trunk, and caudal peduncle) measure $48 \mathrm{~cm}$ in length. Because the caudal fin is missing the total body length of the holotype can only be estimated at $55-60 \mathrm{~cm}$.

\section{Endochondral Neurocranium}

Of the endochondral neurocranium the basioccipital, exoccipital, epiotic, prootic, and sphenotic are preserved.

Basioccipital (Figs. 2, 3; Boc)-The basioccipital is a massive ossification that forms the posteroventral floor of the braincase. Its posterior portion, which lacks a superficial layer of perichondral bone, lodges a wide conical pit for the insertion of the anterior end of the notochord. Posteroventrolateral to the notochordal pit a pair of stout and flattened processes are developed. On their distal end each of these processes bears a facet for the articulation of a pair of cranial ribs (Fig. 3, fri). Similar facets have been found in L. toombsi and L. latifrons (Patterson, 1975). The lateral wall of the basioccipital is pierced by a foramen for the occipital artery (Fig. 3, oca).

Exoccipital (Figs. 2, 3; Exo)-The exoccipital forms the posteroventral part of the neurocranial wall. It is a curved ossification of irregular shape that posteriorly meets its counterpart in the median plane of the skull. Immediately above the notochordal pit in the basioccipital the posterior edges of the left and right exoccipital retreat from each other to form a large median foramen, the foramen magnum. Laterally the exoccipital is pierced by an almost horizontal row of five foramina. The most anterior of these differs from the others by its larger size (Fig. 3, X). It transmitted the vagus nerve $(\mathrm{N}$. X). In accordance with $L$. toombsi (Patterson, 1975) the four posteriorly following foramina represent openings for the roots of occipital nerves (Fig. 3, ocn). Behind each occipital nerve foramen is a vertical crest that served for the insertion of an intermuscular septum. As in L. toombsi (Patterson, 1975) the exoccipital enclosed the lower part of the posterior semicircular canal as indicated by a groove on the broadened upper edge of the ossification (not shown in Fig. 3). Additionally, Patterson (1975) found a process on the ridge separating the posterior and lateral surfaces of the exoccipital in L. toombsi that he interpreted as homologous with the intercalar of holosteans and teleosts. In USNM 279856, however, such a process seems to be lacking.

Epiotic (Figs. 2, 3, 6; Epi)-The epiotic forms the posterodorsolateral part of the braincase. The dorsal, 

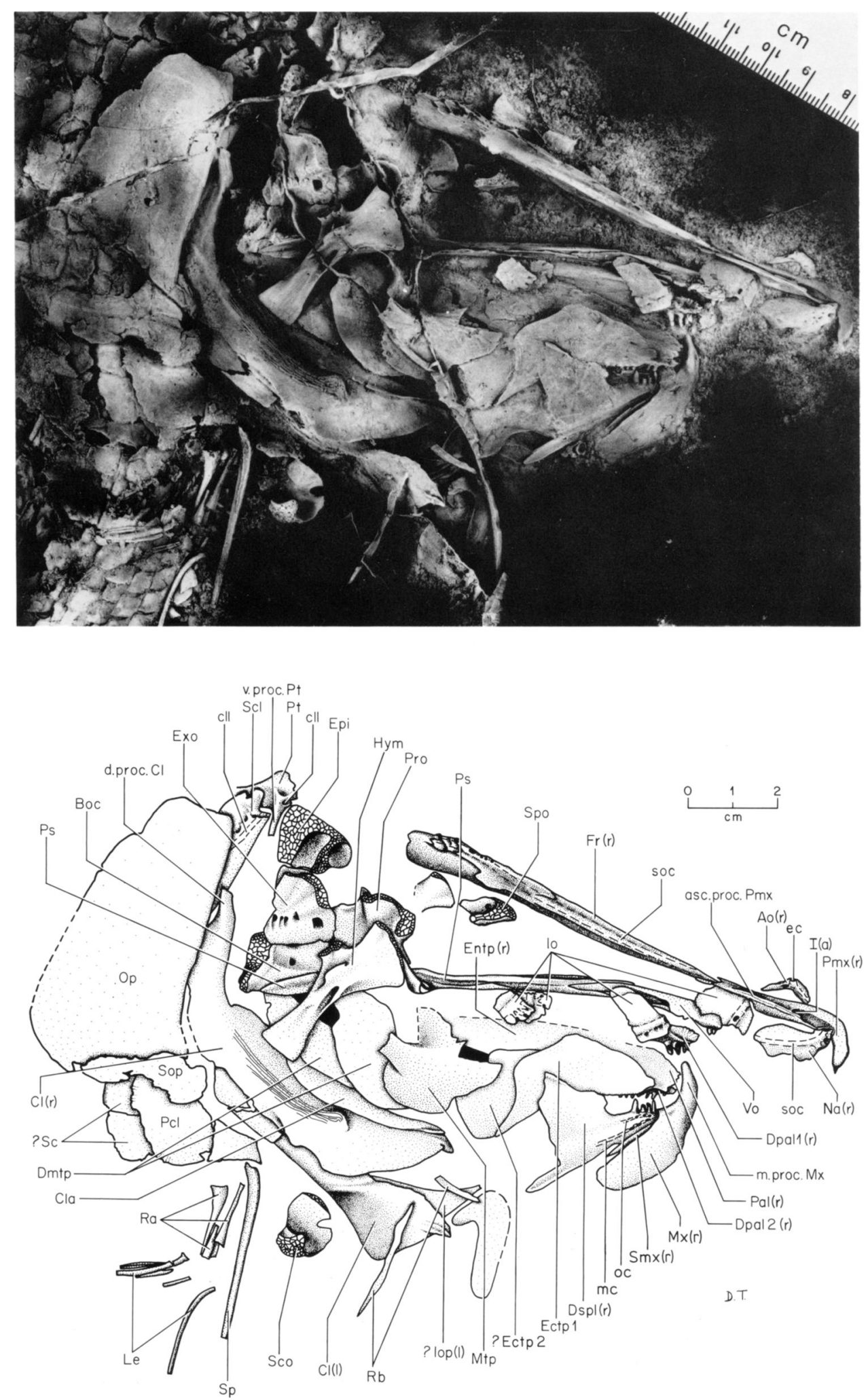

FIGURE 2. Lepidotes gloriae, sp. nov. (holotype, USNM 279856, part). Right side of skull. 


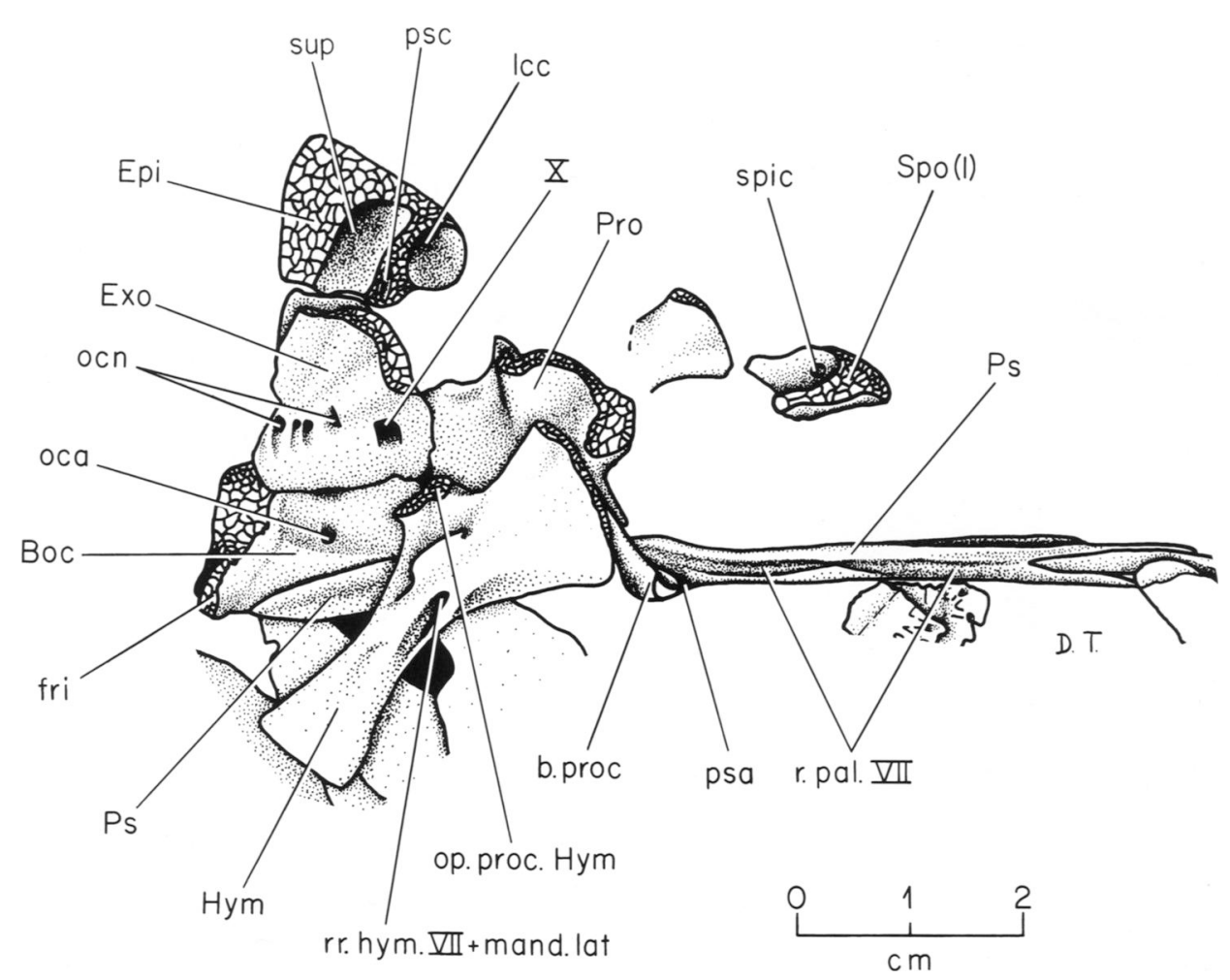

FIGURE 3. Lepidotes gloriae, sp. nov. (holotype, USNM 279856, part). Endochondral neurocranium, right hyomandibula, and parasphenoid. Lateral view.

posterior, and lateral surfaces of the ossified part are oriented almost at right angles to each other. As shown in Figure 6 a pronounced process extends from the lateral upper corner of the bone posteriorly (into the trunk musculature; Patterson, 1975). The medial surface displays two deep, blind pits. The anterior, smaller one (Figs. 3, 6; lcc) was considered to be homologous with the lateral cranial canal of other actinopterygians by Patterson (1975). The function of the posterior, larger pit (Figs. 3, 6; sup) is still obscure. The wall of bone separating these two pits bears an inconspicuous, shallow groove (Figs. 3, 6; psc), which indicates that the upper part of the posterior semicircular canal was enclosed by the epiotic.

According to Jarvik (1980) and Bjerring (1984) the lateral cranial canal most probably housed a lateral diverticulum of a lymph-forming organ ("epimyelencephalic lymphomyeloid organ"). This organ seems to differ considerably in its shape and formation of lateral diverticula even within the same species (e.g., Lepisosteus osseus; Bjerring, 1984). It might therefore be possible that both large cavities in the epiotic of Lepidotes accommodated lateral diverticula of the lymphomyeloid organ (although two pairs of lateral diverticula have not yet been observed on this organ).

Prootic (Figs. 2-4; Pro) - The prootic completes the ventral part of the braincase behind the orbit. The irregularly shaped bone has a lateral and an orbital surface separated by a strong vertical ridge. A down- wardly directed foramen for the glossopharyngeal nerve (N. IX) penetrates the lateral surface, but in USNM 279856 it is hidden beneath the upper part of the hyomandibula, which partly covers the lateral surface of the prootic. For the same reason the exact position and shape of the foramen for the hyomandibular trunk of the facial nerve (N. VII) must remain obscure in USNM 279856. The spiracular canal (Fig. 4, spic), which is enclosed in the vertical ridge separating the lateral and the orbital part of the prootic, enters the bone through a foramen on the posterior surface of this ridge (as in Amia calva and L. toombsi; Allis, 1897; Patterson, 1975). In USNM 279856 this foramen is also hidden by the overlying hyomandibula. However, its existence and position can be demonstrated by inserting a hair into the upper opening of the spiracular canal. Medial to the spiracular canal another dorsally directed canal is incorporated into the prootic (Fig. 4, r. ot. lat). A similar canal in the recent Amia calva (Allis, 1897) contains the otic branch of the lateralis nerve (="ramus oticus VII"; for discussion of sensory canal nerve supply in Amia see Jarvik, 1980). In living chondrosteans and holosteans this nerve branch supplies a neuromast organ lodged near the top of the spiracular canal (Gardiner, 1984). In L. toombsi the otic canal has been found to join the spiracular canal in the sphenotic (Patterson, 1975).

On the orbital surface the anterior opening of the trigeminofacial chamber is developed as a large recess 

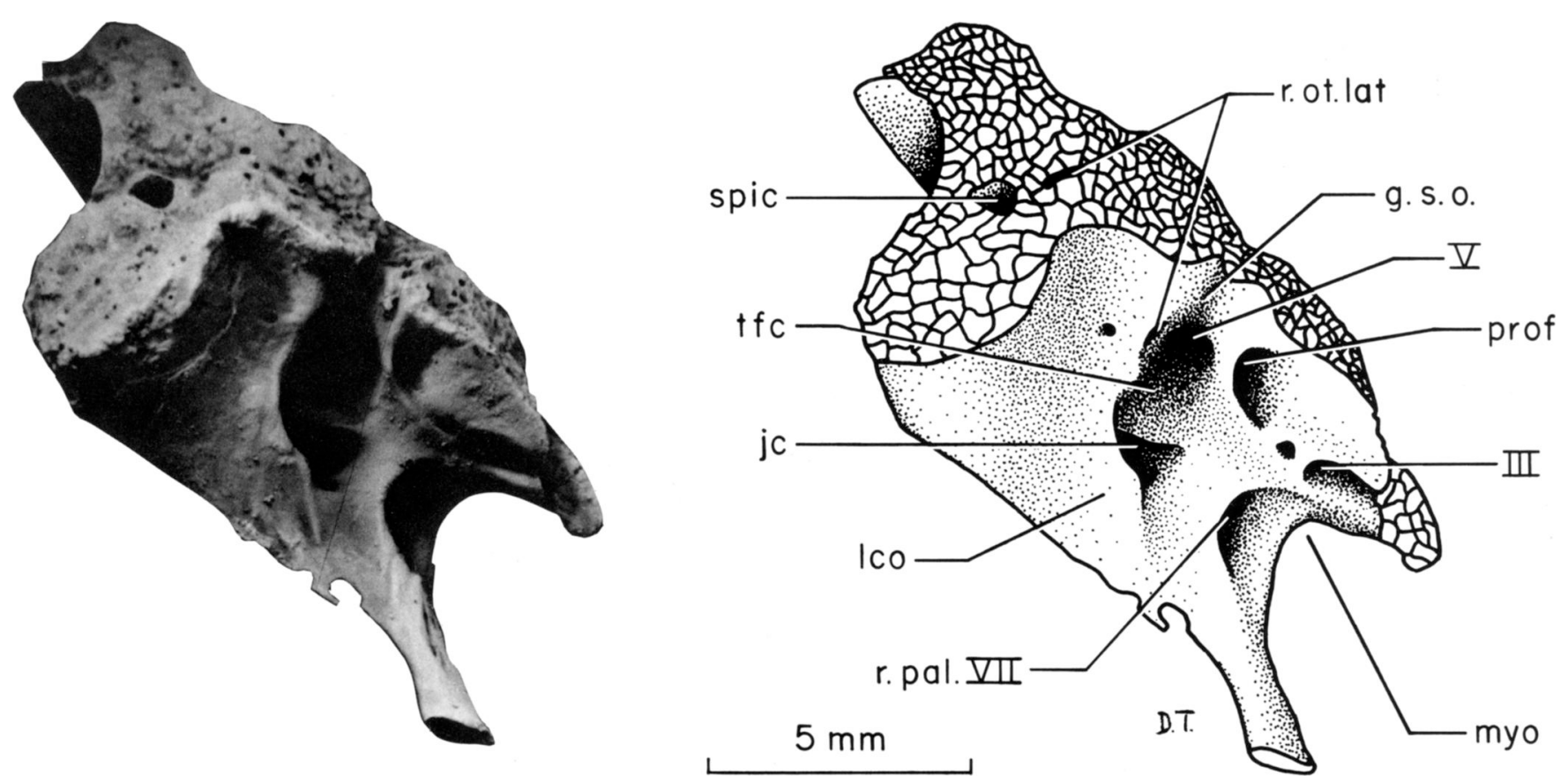

FIGURE 4. Lepidotes gloriae, sp. nov. (holotype, USNM 279856, part). Right prootic. Anterior view.

in the center of this surface (Fig. $4, \mathrm{tfc}$ ). (The term "trigeminofacial chamber" is used here in the sense of Schaeffer, 1971). The large foramen in the upper anteromedial corner of the chamber represents the opening for the trigeminal nerve (N. V) (Fig. 4, V). Below and slightly lateral to the trigeminal foramen the jugular canal opens into the orbit (Fig. 4, jc). Laterally the chamber is bridged by a short, stout lateral commissure (Fig. 4, lco). The small foramen in the roof of the anterior opening of the trigeminofacial chamber is the ventral opening of the otic canal by which the otic nerve entered the prootic (Fig. 4, r. ot. lat). As in other species of Lepidotes (Patterson, 1975) the orbital surface of the prootic of USNM 279856 lacks separate foramina for the superficial ophthalmic nerves. Gardiner (1984) assumed that these nerves passed through the trigeminal foramen. If this assumption is correct the deep groove above the trigeminal foramen between the trigeminofacial chamber and the (presumed) prootic/pterosphenoid boundary has most likely been left by the superficial ophthalmic nerves (Fig. 4, g.s.o).

Anterior to the trigeminofacial chamber three more foramina are located on the orbital surface of the prootic. The most dorsal of these transmitted the profundus nerve (Fig. 4, prof). The second foramen is slitlike and situated at the (presumed) prootic/basisphenoid boundary. It transmitted the oculomotor nerve (N. III) (Fig. 4, III). The palatine branch of the facial nerve (N. VII) left the prootic through the anteromedially directed third foramen, which is placed ventral to the profundus and oculomotor foramina in the roof of the posterior myodom (Fig. 4, r. pal. VIII). With its anteroventral surface the prootic takes part in the for- mation of the roof and lateral wall of the posterior myodom (Fig. 4, myo).

In summary, the prootic of USNM 279856 resembles those of Lepidotes semiserratus, L. toombsi, $L$. latifrons, and L. mantelli in the development and arrangement of the foramina and canals piercing the bone (Rayner, 1948: figs. 11, 12; Gardiner, 1960: figs. 4466; Patterson, 1975; figs. 108-110). It differs, however, considerably from the prootic of $L$. deccanensis, which has been described and figured by Jain (1983: pl. 3) as lacking the otic canal but instead having developed two separate canals for the superficial ophthalmic nerves.

Sphenotic (Figs. 2, 3; Spo) - The sphenotic seems to be only partly preserved on the acid-prepared part of USNM 279856, the rest of the bone being contained in the counterpart. Thus, the exact shape of the bone, which was detached after death from the prootic and shifted into the orbit, remains obscure. The (presumed) dorsal surface shows a single foramen (Fig. 3, spic) that I interpret as the dorsal opening of the spiracular canal (assuming that within the sphenotic, as in L. toombsi, the otic canal runs into the spiracular canal).

Patterson's brief account of the course of the spiracular and otic canals in the sphenotic of $L$. toombsi is a little confusing. On the one hand, he wrote that the otic canal joins the spiracular canal in the sphenotic (Patterson, 1975). On the other hand, in the reconstruction of the neurocranium of $L$. toombsi he has (?erroneously) labeled the single foramen on the dorsal surface of the sphenotic as the upper foramen for the otic nerve (Patterson, 1975: fig. 108).

The orbital part of the braincase of Lepidotes is 
formed by a median basisphenoid and orbitosphenoid and a paired pterosphenoid (Rayner, 1948; Gardiner, 1960; Patterson, 1975; Jain, 1983). None of these ossifications are preserved in USNM 279856. Their loss was presumably postmortem.

Ethmoidal neurocranial ossifications have not yet been reported from Lepidotes with certainty. In a skull reconstruction of $L$. semiserratus Holmgren and Stensiö (1936: fig. 364) figured an ectethmoid and a preethmoid. However, Rayner (1948) doubted the presence of these bones in the particular specimen used by Holmgren and Stensiö.

\section{Dermal Neurocranium}

All dermal neurocranial bones lack a superficial cover of ganoin.

Parietal (Figs. 6, 7; Pa)-The form of the parietals that have been preserved isolated from the skull can roughly be described as rectangular. Left and right parietals are of nearly equal size. The median suture between them is interdigitate. The left parietal shows some vestigial tubercles on its external surface, otherwise both parietals are smooth. The supraorbital canal (Figs. 6, 7; soc) enters the bone at its anterolateral corner and runs about halfway along its lateral edge. A transverse canal near the posterior edge in both parietals conveyed a portion of the supratemporal commissure (Figs. 6, 7; st). There are no traces of pit lines on the parietals.

Dermopterotic (Fig. 8)-Only the right dermopterotic of USNM 279856 is preserved. Like the parietals it became detached from the skull after death. It is a massive, elongated, and irregularly shaped ossification. The central part of the dorsal surface is pierced by numerous pores, which may have transmitted blood vessels. The infraorbital canal (Fig. 8, ioc) is deeply embedded into the dermopterotic and traverses the bone some distance from its lateral edge. It sends off small tubules that open on the dorsal surface in the vicinity of its lateral edge. Anteriorly the infraorbital canal sends off a medioanteriorly directed branch (Fig. 8 , mbioc). This branch continues into the frontal where its further course remains obscure. A second canal can be observed in the posterior part of the dermopterotic (Fig. 8, mpl). It is oriented transversely and lies above the infraorbital canal. This canal obviously represents the equivalent of the dermopterotic portion of the median pit line of the skull roof.

Frontal (Figs. 2, 5; Fr)-The frontals are rather narrow, anteroposteriorly elongated plates of bone. They are about three times as long as the parietals, having their greatest width just behind the orbit. The postorbital part of each frontal is gently curved mediolaterally. As far as can be judged from USNM 279856 the median suture between the right and left frontals is almost straight. The course of the supraorbital canal (Figs. 2, 5; soc) in front of and above the orbit can easily be traced by a prominent ridge on the medial side of the bone close to its lateral edge. The postorbital course of the supraorbital canal cannot be observed directly, but from the lateral position of this canal in the parietals (Figs. 6, 7; soc) it is concluded that in the posterior part of the frontals the supraorbital canal also runs near the lateral edge of the bone. On the anterior part of the frontal the canal opens through one or two large, slit-like foramina that are placed immediately above the sensory canal (Fig. 2). Unfortunately, USNM 279856 does not reveal the number, shape, and arrangement of the supraorbital sensory canal pores on the posterior part of the frontals. The four foramina on the postorbital lateral edge of the right frontal (Fig. 2) might belong to the medioanterior branch of the infraorbital canal, which, originating in the dermopterotic (see above; Fig. 8, mbioc), presumably enters the frontal a little posterior to the hindermost and largest of these foramina.

Nasal (Figs. 2, 5; Na)-Both nasals are present in USNM 279856. While the right nasal (Fig. 2, $\mathrm{Na}(\mathrm{r})$ ) is preserved completely, only a fragment of the left nasal appears on the counterpart (Fig. 5, $\mathrm{Na}(\mathrm{l})$ ). The external surface is smooth, its outline is roughly oval. The supraorbital canal (Figs. 2, 5; soc) traverses the nasals longitudinally producing only a few pores at the anterior edge of the bone.

Antorbital (Figs. 2, 5; Ao)-Both antorbitals are visible on USNM 279856 with the left one (Fig. 5, Ao(l)) nearly completely preserved. Being developed as a narrow and boomerang-shaped ossification, the antorbital of USNM 279856 corresponds morphologically to the antorbital of Lepidotes minor (Patterson, 1975: fig. 135) and L. elvensis (Wenz, 1967: figs. 43-45, "Ros"). (Patterson, 1975 indicated that the bones identified by Wenz in $L$. elvensis as a paired rostral most probably represent the antorbitals.) The canal for the ethmoidal commissure (Figs. 2, 5; ec) is restricted to the anteromedially directed branch of the antorbital (="anterior process of the antorbital" sensu Patterson, 1975) leaving the posterior branch as a solid strut of bone.

Infraorbital (Figs. 2, 5; Io)-The infraorbital series is incompletely preserved. Some small, roughly rectangular bony plates, all of them traversed by a canal (Figs. 2, 5; ioc) and lying in or around the orbit of part and counterpart of USNM 279856, can be identified as infraorbitals. The fragmentary nature of the remains does not allow any conclusions about the exact number and arrangement of elements in the infraorbital series of USNM 279856.

Parasphenoid (Figs. 2, 3; Ps)-The parasphenoid is visible in lateral view in USNM 279856. Its anterior part is still in contact with the vomer, which articulates with the ventral surface of the parasphenoid. The surface of articulation for the vomer measures approximately one third of the length of the anterior part of the parasphenoid in front of the basipterygoid process. Beginning just in front of the posterior myodome a deep paired groove on the dorsal surface of the parasphenoid runs forward and laterad. It gradually passes onto the ventral surface and ends a little behind the tip of the posterior flange of the vomer (Fig. 3, r. pal. 

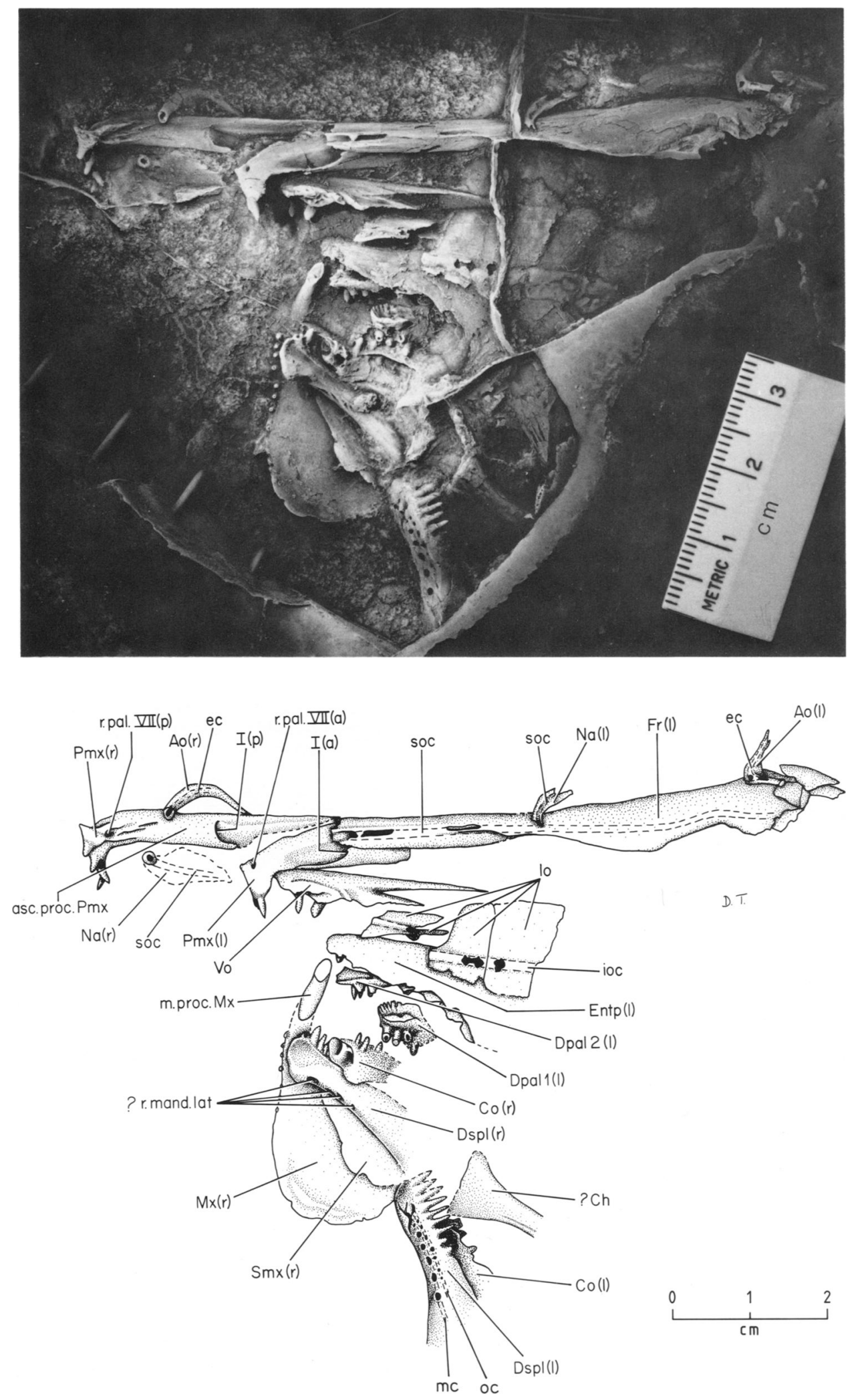

FIGURE 5. Lepidotes gloriae, sp. nov. (holotype, USNM 279856, counterpart). Left side of skull. 

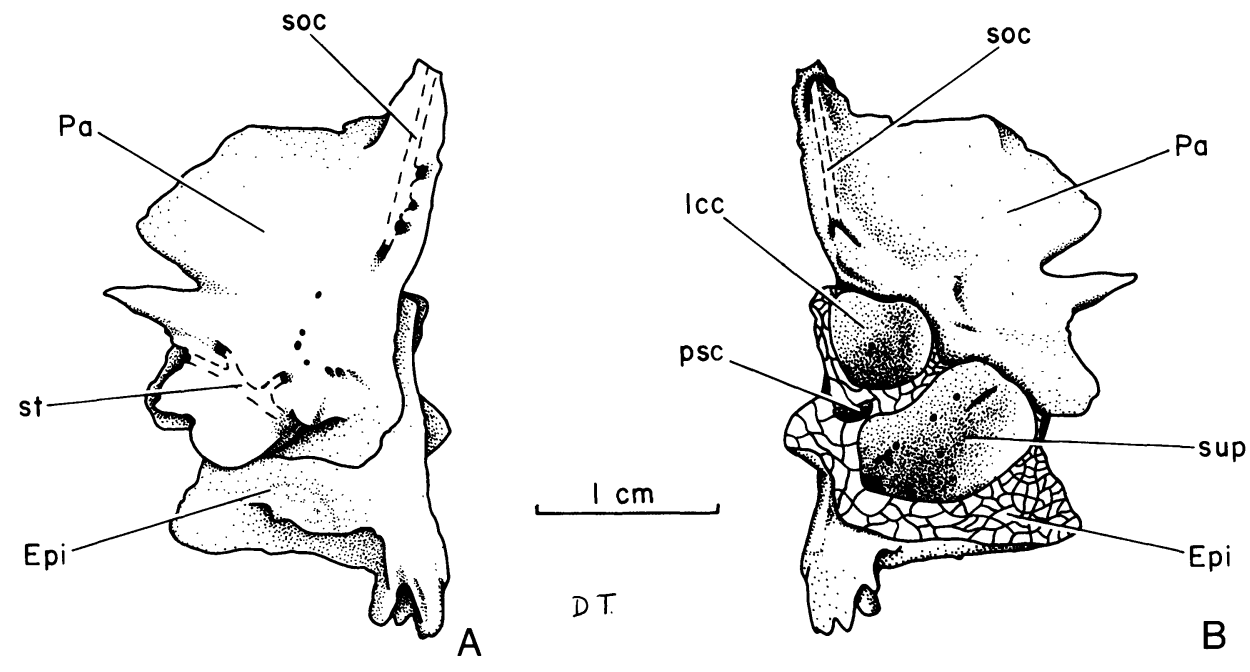

FIGURE 6. Lepidotes gloriae, sp. nov. (holotype, USNM 279856). Right epiotic and parietal. A, dorsal (external) view. B, ventral (internal) view.

VII). This groove must have lodged the palatine branch of the facial nerve (N. VII). The strongly developed basipterygoid process (="anterior ascending process" sensu Jain, 1983) is directed anterolaterad (Fig. 3, b. proc). Its tip is broken off thus producing a cross section of the basipterygoid process of the parasphenoid, which reveals the existence of a deep gutter on the dorsal surface of the proximal part of the process. Such a gutter has previously been described in Lepidotes latifrons and L. deccanensis (Rayner, 1948; Jain, 1983). Rayner (1951) and Patterson (1975) have pointed out that in certain actinopterygians the basipterygoid process is a compound structure formed in part by the endochondral neurocranium and by the parasphenoid, which wraps around the neurocranial component. Accordingly, the above described gutter on the dermal basipterygoid process of USNM 279856 should have contained a neurocranial (=basisphenoid) component. Patterson (1975) assumed that the neurocranial component of the basipterygoid process was ossified in large individuals of Lepidotes. However, USNM 279856 does not support this assumption. This specimen was certainly a large adult but the basisphenoid component of the basipterygoid process seems to have been formed by cartilage only. No traces of an endochondral ossification were found in the dorsal gutter on the basipterygoid process.

A deep lateral notch on the anterior part just in front of the basipterygoid process (Fig. 3, psa) marks the passage of the efferent pseudobranchial artery (Rayner, 1948). An identical or similar notch occurs in Lepidotes deccanensis, L. latifrons, and L. minor (Woodward, 1893, 1916; Rayner, 1948; Jain, 1983).

The posterior portion behind the basipterygoid process is partly covered by the hyomandibula in USNM 279856 leaving only its posterior end free. This end is developed into a pair of lateral flanges each of which carries a vertical lamella on its ventral side. In this way the posterior end of the parasphenoid together with the ventral side of the basioccipital forms a groove for the dorsal aorta (Patterson, 1975; Jain, 1983).

The parasphenoid of USNM 279856 does not bear teeth.

Vomer (Figs. 2, 5; Vo)-Patterson (1973) stated that in Lepidotes the vomer is a median ossification. However, Jain (1983) found that in small individuals of $L$. deccanensis the vomer is paired, becoming co-ossified in larger individuals but still showing a median suture. In USNM 279856, which represents a large, adult individual, the vomer also is a median ossification with the left half preserved on the part (Fig. 2, Vo) and the right half on the counterpart (Fig. 5, Vo). The massive anterior part bears two transverse rows of teeth. The number of teeth in each row can only be estimated but must not have exceeded six. All vomerine teeth are tall, cylindrical, and pointed. As in other species of Lepidotes (e.g., L. deccanensis; Jain, 1983: fig. 5B) the anterior teeth are styliform whereas the posterior ones are more robust.

The hinder part is developed into a pair of large

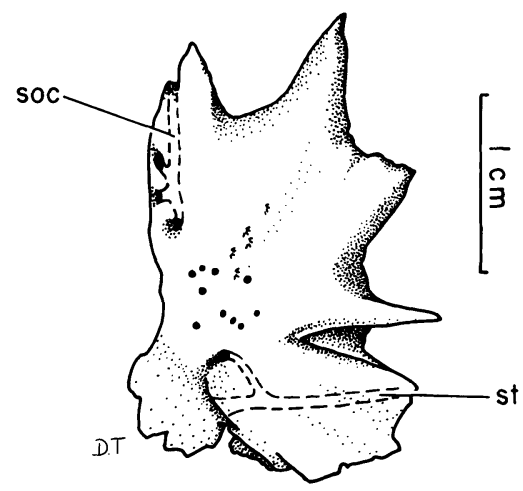

FIGURE 7. Lepidotes gloriae, sp. nov. (holotype, USNM 279856). Left parietal. External view. 
posterior processes that articulate with the ventral surface of the parasphenoid (Fig. 2).

The extrascapular(s), suborbitals, supraorbital(s), and the rostral were lost after death in USNM 279856.

\section{Visceral Skeleton \\ Mandibular Arch \\ Endochondral Elements}

Metapterygoid (Fig. 2, Mtp)-Only the right metapterygoid of USNM 279856 is preserved. It is a thin bone, which is slightly curved dorsoventrally. Its outline is rounded and leaf-shaped. On its external surface near the hinder margin of the bone originates a strong posterior process (="processus otique" sensu Wenz, 1967) that is directed dorsally and posteriorly. In its general morphology the metapterygoid of USNM 279856 resembles those of Lepidotus semiserratus and L. latifrons (Woodward, 1893; Rayner, 1948) but it differs considerably from those of $L$. lennieri and $L$. mantelli, which seem to be more elongated longitudinally and pointed anteriorly (Gardiner, 1960; Wenz, 1967). The metapterygoid of $L$. latifrons, which was figured and described by Woodward (1893) as the left, instead appears to be the right metapterygoid. This is indicated by the position and orientation of its process, which is directed posteriorly as shown by USNM 279856 , and not anteriorly as stated by Woodward.

Rayner (1948) and Jain (1983) have stated that in Lepidotes semiserratus and in L. toombsi, respectively, the metapterygoid articulates with the basipterygoid process of the parasphenoid. However, USNM 279856 does not provide any evidence for the existence of such an articulation. Rather, it is more likely that in Lepidotes the metapterygoid was connected to the postorbital process (sphenotic) by a muscle that inserted (at least partly) at the posterior process. A connection of this kind is realized in the Recent Amia calva, which possesses a metapterygoid very similar to that found in USNM 279856. In Amia the metapterygoid is linked to the postorbital process (sphenotic) by the $\mathrm{m}$. levator arcus palatini, which originates at the postorbital process and inserts on the posterodorsal process and on the upper outer surface of the metapterygoid (and on the outer surface of the hyomandibula) (Allis, 1897).

Entopterygoid (Figs. 2, 5; Entp)-On the part (Fig. 2) that displays the right entopterygoid large portions of the bone are hidden under the metapterygoid and the ectopterygoid 1. From what is visible it appears that the entopterygoid is a narrow strip of bone, elongated longitudinally and slightly curved dorsoventrad. While there is a distinct suture between the (right) entopterygoid and the bone labelled ?Ectp 2, no such suture occurs between the entopterygoid and the palatine (Fig. 2). It seems that the entopterygoid and the palatine are coossified in USNM 279856.

The left entopterygoid is preserved only fragmentarily on the counterpart, ventrolateral parts of the bone being broken off (Fig. 5, Entp (1)). The lateral fracture surface on the left entopterygoid shows that

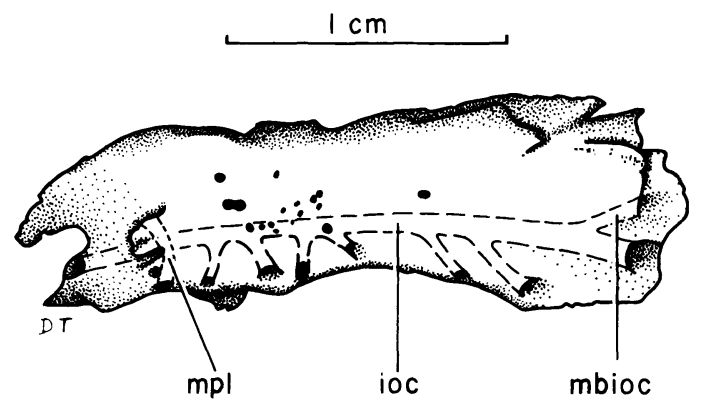

FIGURE 8. Lepidotes gloriae, sp. nov. (holotype, USNM 279856). Right dermopterotic. External view.

the entopterygoid of USNM 279856 reaches a considerable thickness.

Palatine (=autopalatine; Fig. 2, Pal)-The palatine is developed as a thin lamella of bone, slightly curved dorsoventrally. Posteriorly it seems to be fused with the entopterygoid, so that its exact shape and dimensions remain obscure. Its anterior edge is rounded and shows some indentations. The dermopalatine 2 is attached to the anterolateral part of the internal surface of the palatine as shown by the part (Fig. 2). USNM 279856 does not reveal the position of the attachment of dermopalatine 1 to the palatine because after death dermopalatine 1 lost direct contact with the palatine on either side of the fossil (Figs. 2, 5; Dpal 1).

In its sheet-like appearance the palatine of USNM 279856 differs markedly from those of Lepidotes mantelli, L. lennieri, and L. elvensis, which have been described as being massive and stout (Gardiner, 1960; Wenz, 1967).

Quadrate (Fig. 9)-Only the right quadrate is preserved in USNM 279856. It is a small bone roughly triangular in shape. Its upper portion is sheet-like with a rounded upper edge. The lower part is developed into a massive condyle for the mandibular articulation. The lateral surface bears a high, narrow crest along the ventral edge. A wing-like expansion extends from the hinder edge of the quadrate condyle. As demonstrated by Patterson (1973) in Lepidotes sp. the quadratojugal (not preserved in USNM 279856) abuts the lateral crest and this wing-like expansion.

The quadrate of USNM 279856 bears a strong resemblance to the quadrate of Lepidotes latifrons and L. lennieri (Woodward, 1893; Wenz, 1967). (In his figs. 4 and 5 Woodward, 1893 has confused the inner and outer aspect of the quadrate of $L$. latifrons. Therefore, fig. 4 shows the left and not the right quadrate, as indicated by the presence of a crest on the lateral surface, while the bone in his fig. 5 represents the right quadrate. The bone of $L$. elvensis identified by Wenz (1967) as the quadrate is probably not the quadrate but may correspond to the palatal element of USNM 279856 that I have termed ?ectopterygoid 2; see below.) The position of the quadrate relative to the other palatal elements remains obscure in USNM 279856 because the bone was displaced after death from its 

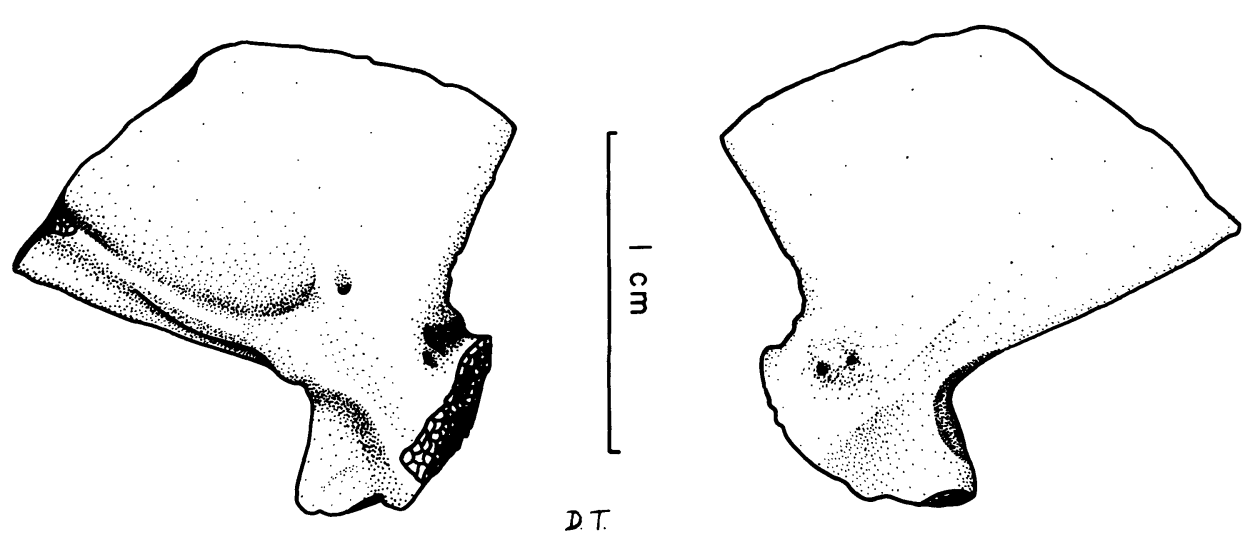

A

B

FIGURE 9. Lepidotes gloriae, sp. nov. (holotype, USNM 279856). Right quadrate. A, lateral view. B, medial view.

original position and was found isolated from the palatal arcade.

Further endochondral ossifications of the mandibular arch cannot be observed on USNM 279856.

\section{Dermal Elements}

Premaxilla (Figs. 2, 5; Pmx)-Both premaxillae are preserved in USNM 279856. Anteriorly the premaxilla consists of a narrow, transverse strip of bone that bears a single series of seven long, styliform, and sharply pointed teeth on its ventral surface. A terminal branch of the palatine nerve entered this strip of bone through a foramen on its posterior edge (Fig. 5, r. pal. VII(p)) and emerged through a second foramen on its dorsal surface (Fig. 5, r. pal. VII(a)). In Lepidotes lennieri the latter foramen is placed far more posteriorly on the premaxilla (Wenz, 1967). From the median extremity of the tooth-bearing part of the premaxilla an ascending process (="nasal process" sensu Patterson, 1973) projects posteriorly far below the frontal bone (Figs. 2, 5; asc. proc. Pmx). This process considerably exceeds the anterior transverse tooth-bearing part in length. Longitudinally the ascending process is penetrated by a wide canal for the olfactory nerve (N. I) (Figs. 2, 5; $\mathrm{I}(\mathrm{a}), \mathrm{I}(\mathrm{p}))$. The canal continues anteriorly as a wide, deep groove that may have taken part in the formation of the nasal pit (as in Amia calva and Semionotus canabensis where the ascending process of the premaxilla has been found to form a part of the floor of the nasal pit; Allis, 1898; Holmgren and Stensiö, 1936; Schaeffer and Dunkle, 1950).

Maxilla (Figs. 2, 5; Mx)-Only the right maxillary bone is preserved in USNM 279856. The upper portion can be seen on the part (Fig. 2); the lower portion is displayed on the counterpart (Fig. 5). As in other semionotids the maxilla is a thin lamella of bone, narrow anteriorly and becoming wider posteriorly, with a rounded posterior edge. The anteroventral edge of the maxilla bears eight or nine small, conical, and widely spaced teeth. The anterior extremity of the bone is developed as a strong, almost cylindrical median pro- cess (Figs. 2, 5; m. proc. Mx). This process is supposed to have extended below the ventral surface of the premaxillary bone (Wenz, 1967).

Supramaxilla (Figs. 2, 5; Smx) - The maxillary apparatus in USNM 279856 is completed by a supramaxillary bone. Only the right supramaxilla is visible and, like the maxilla, this bone is preserved in two portions on part and counterpart. The supramaxilla is oval or ovoid in shape.

Dermopalatines 1 and 2 (Figs. 2, 5; Dpal 1, Dpal 2)-Gardiner (1984) stated that there is only one pair of dermopalatines in Lepidotes. In USNM 279856, however, there are two pairs.

Dermopalatine 1 (Figs. 2, 5; Dpal 1) is a relatively small, but stout and massive ossification bearing three transverse series of cylindrical, apically pointed teeth on its oral surface. In the right dermopalatine 1 the anterior and posterior series each have two teeth; the middle series has three teeth. The lateral side of dermopalatine 1 is developed into a deep, oval-shaped pit. The wall of this pit is deeply serrated in its anterodorsal, anterior, and anteroventral parts. This pit supposedly provides an articular surface for the palatine. Both dermopalatines 1 have become detached from the palatines in USNM 279856 after death. Their exact position and orientation in the roof of the mouth remains obscure in the specimen. In its appearance the dermopalatine 1 of USNM 279856 resembles the dermopalatine of Lepidotes elvensis (Wenz, 1967).

Dermopalatine 2 (Figs. 2, 5; Dpal 2) is smaller than dermopalatine 1 and also differs from the latter in that it is a less massive ossification. In transverse view the dorsal surface of dermopalatine 2 is concave whereas the tooth-bearing ventral surface is convex. The right dermopalatine 2 is still in its original position being attached to the anterolateral part of the ventral surface of the palatine (Fig. 2). The lateral edge of the bone is thickened and seems to wrap around the lateral edge of the palatine. Five teeth arise from each of the oral surfaces of right and left dermopalatines 2 , which are identical with those on dermopalatine 1. Apart from the dentition the dermopalatine 2 of USNM 279856 
resembles the so-called "pterygo-palatine" of Lepidotes mantelli in shape and morphology (Woodward, 1916).

Ectopterygoid 1, ?Ectopterygoid 2 (Fig. 2; Ectp 1, ?Ectp 2)-The anterolateral part of the palate is formed by two thin, sheet-like ossifications. The larger, anterior one (Fig. 2, Ectp 1) is elongated and of irregular shape. Its dorsomedial edge is irregularly rounded; the ventrolateral edge is concave. This anterior ossification covers a large part of the external surface of the palatine and of the entopterygoid, and like these elements the bone is slightly curved ventrodorsad. Six medium-sized, cylindrical, and pointed teeth are visible on the internal surface along the anterior part of the ventrolateral edge of the bone. The true extent of the dentition on the internal surface of this ossification remains uncertain in USNM 279856. Its anterolateral position in the palatal arcade leaves no doubt that it represents an ectopterygoid. An ectopterygoid of similar shape has been found in Lepidotes elvensis, though the bone is much narrower in this species (Wenz, 1967).

Posteriorly the ectopterygoid 1 is followed by a second, smaller ossification (Fig. 2, ?Ectp 2). Because this bone is partly covered by the hinder portion of the ectopterygoid 1 anteriorly and the anterior portion of the metapterygoid posteriorly its exact outline remains obscure. Dorsomedially it borders the entopterygoid as shown by a distinct suture. Like the neighboring bones it is slightly curved ventrodorsad. A determination of the homologies of this bone is not yet possible. Amia calva has only one pair of ectopterygoids that are in contact with the metapterygoids (Jarvik, 1980). An ossification, similar to ?Ectp 2 in regard to its relation to the ectopterygoid, occurs in Lepidotes elvensis where it is apparently also covered by the ectopterygoid anteriorly. Wenz (1967) referred to this bone in L. elvensis as the quadrate. However, the quadrate is well known in USNM 279856 (see above) and is quite different from the ?Ectp 2 (as well as from the ossification in L. elvensis Wenz identified as the quadrate). Because the ?Ectp 2 is in contact with the entopterygoid dorsomedially, with the metapterygoid posteriorly, and (presumably) with the quadrate ventrolaterally, I tentatively interpret this ossification as a second (posterior) ectopterygoid although a second pair of ectopterygoids has not yet been found in any other living or fossil actinopterygian.

Dermometapterygoids (Fig. 2, Dmtp)-The roof of the mouth of USNM 279856 is completed by two further sheet-like, paired ossifications posterior and medial to the metapterygoid. As far as can be judged from their visible parts both bones are of irregular shape, elongated in dorsoventral direction, and have a convex posterior edge. Their external surface is smooth. It is not clear from USNM 279856 whether or not they bear teeth on their internal surface. The anterior, slightly larger of these two bones partly overlaps the posterior one. The anterior ossification is, in turn, overlapped by the metapterygoid anteriorly. Because the anterior bone is in contact with the medial face of the metapterygoid (and might have bordered the entopterygoid anteriorly) I homologize the two bones in question with the dermometapterygoid of Amia calva (Jarvik, 1980). Primitive fossil actinopterygians are reported to have up to five pairs of dermometapterygoids (Gardiner, 1984). In Lepidotes dermometapterygoids have not previously been described.

Dentalosplenial (Figs. 2, 5; Dspl)-The complete right and the anterior portion of the left dentalosplenial are preserved in USNM 279856. The anterior half of the bone is narrow and strongly bent towards the median plane to meet its counterpart in the symphysis. The lateral side of the anterior part is convex; the medial side is concave near the symphysis. Along its upper edge the anterior narrow part of the dentalosplenial bears a single series of eight to ten long, styliform, and pointed teeth that equal the premaxillary teeth in size. In its posterior half the dentalosplenial widens rapidly and takes part in the formation of the coronoid process. The posterior edge is almost straight and vertical. A long, narrow process extends backwards from the posteroventral corner.

Two longitudinal canals are present in the anterior narrow part of the dentalosplenial lying one above the other (Figs. 2, 5; oc, mc). Both canals have their anterior extremity near the symphysis. Laterally each canal opens separately through its own row of pores. The upper row is shorter than the lower one and its pores are slightly smaller in diameter. Because the formation of pores is restricted to the anterior, narrow part of the dentalosplenial the exact course of the canals cannot be traced on its posterior part. I assume that the dorsal canal (Figs. 2, 5; oc), which is referred to here as the oral canal, is limited to the anterior half of the dentalosplenial. The ventral canal (Figs. 2, 5; mc) seems to continue posteriorly through the posterior half (into the angular, which, however, is not preserved in USNM 279856) and must represent the mandibular canal.

Some further openings can be observed on the anterior part of the ventral edge of the right dentalosplenial (Fig. 5, ?r. mand. lat). They are fusiform in shape and larger than the sensory canal pores. They lead into tubules (or narrow canals) that connect the oral and mandibular sensory canal with the ventral edge of the bone. Because such openings are unknown in other fossil or living actinopterygians their function remains uncertain. I assume that they served for the nerve supply of the sensory canals by the mandibular branch of the lateralis nerve (="ramus mandibularis externus VII"; for discussion of sensory canal nerve supply in Amia see Jarvik, 1980).

Coronoid (Fig. 5, Co)-One pair of poorly preserved coronoids is visible in USNM 279856. The remains suggest that the coronoids are massive ossifications bearing at least two longitudinal rows of teeth that match the teeth of the dentalosplenial in size and shape.

Only one pair of coronoids occurs in Lepidotes deccanensis, L. minor, and L. mantelli (Woodward, 1916; Jain, 1983) whereas L. elvensis is supposed to have two or three pairs of coronoids (Wenz, 1967; Jain, 1983). 

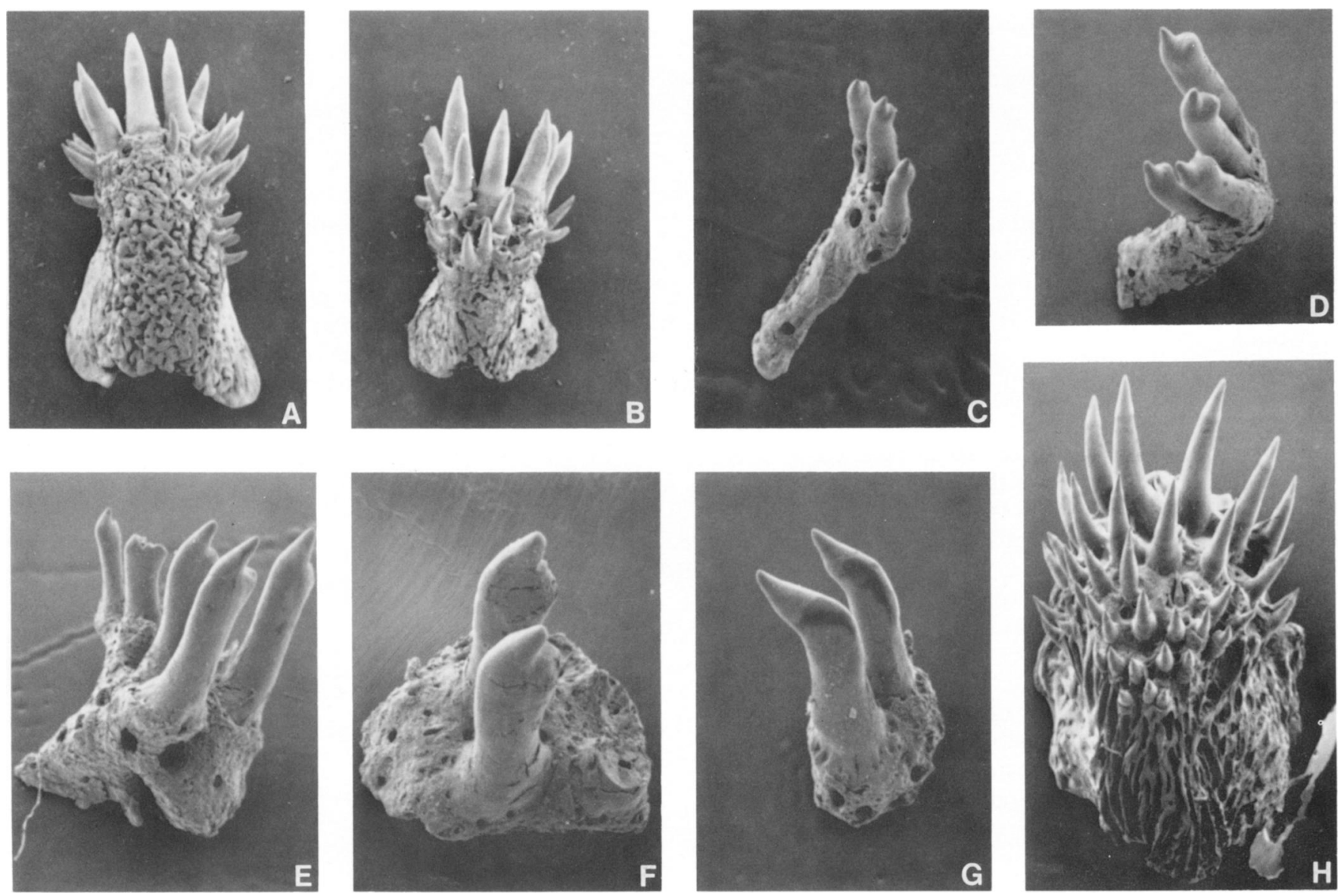

FIGURE 10. Branchial tooth plates. A-G, Lepidotes gloriae, sp. nov. (holotype, USNM 279856). H, Amia calva (KU 21605). All $\times 20$.

Further dermal elements of the mandibular arch are either not preserved or not visible in USNM 279856.

\section{Hyoid Arch \\ Endochondral Elements}

Hyomandibula (Figs. 2, 3; Hym)-The hyomandibula is a slender and compressed strut of bone with a broadened dorsal and a less broadened ventral extremity. A little above the middle of the bone there arises a pronounced opercular process on its posterior edge (Fig. 3, op. proc. Hym). The hyomandibula is pierced by a joint canal for the hyomandibular branch of the facial nerve (N. VII) and the mandibular branch of the lateralis nerve (Jarvik, 1980). It opens on the lateral surface of the hyomandibula through a downwardly directed foramen (Fig. 3, rr. hym. VII + mand. lat). Between this foramen and the opercular process is a sharp, posteriorly directed crest developed on the lateral side of the bone against which the preoperculum must have rested as in Semionotus and many teleosts (Olsen, pers. comm.).

In width the hyomandibula of USNM 279856 resembles those of Lepidotes semiserratus, L. latifrons, and $L$. congolensis, which are also relatively narrow
(Woodward, 1893; Rayner, 1948; Saint-Seine, 1950). The hyomandibulae of $L$. minor and $L$. mantelli are more expanded (Woodward, 1916).

?Ceratohyal (Fig. 5, ?Ch)-A fragment of bone on the counterpart may also belong to the hyoid arch. Being expanded dorsoventrad and laterally compressed at its (assumed) anterior extremity the fragment is similar to the anterior part of the ceratohyal of Lepidotes mantelli (Woodward, 1916). L. mantelli and $L$. elvensis seem to be the only species of Lepidotes in which the epihyal, ceratohyal, and hypohyal are well known (Quenstedt, 1847; Woodward, 1916).

No other endochondral elements of the hyoid arch can be observed in USNM 279856.

\section{Dermal Elements}

Operculum (Fig. 2, Op)-The shape and proportions of the operculum vary to some extent in Lepidotes and have been used as a diagnostic feature by Woodward (1895) (for discussion see Jain, 1983). In the part of USNM 279856 the remains of the (right) opercular apparatus have been shifted after death behind the cleithrum. The operculum is completely smooth on its external face. The anterior border is straight dorsally 
and slightly concave ventrally. The posterior border is convex. The height of the operculum is slightly less than twice its maximum length. These proportions correspond to those of Lepidotes minor, L. leedsi, and $L$. unguiculatus (Woodward, 1895).

Suboperculum (Fig. 2, Sop)-A fragment of bone on the part, ventral to the operculum and partly overlapped by it, can be identified as the suboperculum. Like the operculum the suboperculum is smooth on its external surface. The exact shape of the bone remains uncertain because of its poor state of preservation.

?Interoperculum (Fig. 2, ?Iop)-Another piece of bone on the part might represent the (left) interoperculum. The bone appears to be plate-like and shows its medial side. Its anterior tip is pointed. The expanded posterior portion of the bone is covered mostly by the left cleithrum.

Branchiostegal Rays (Fig. 2, Rb) - The branchiostegal series forms the lowermost part of the opercular apparatus. Only two isolated and detached rays are visible on the part of USNM 279856. As long and narrow strips of bone they extend across the lower end of the left cleithrum and the ?interoperculum, respectively. The exact number of branchiostegal rays remains unknown. In Lepidotes lennieri, Wenz (1967) found six to seven branchiostegal rays. Six rays are also present in L. mantelli (Woodward, 1916).

\section{Branchial Apparatus}

The only remains of the branchial apparatus discovered in USNM 279856 are branchial tooth plates (Fig. 10A-G). These became detached from the branchial arches after death and were found isolated and widely distributed over the head skeleton in the course of preparation. Two morphological types of tooth plates can be distinguished. The first type (Fig. 10A, B) comprises tooth plates that have an expanded and strongly folded basal plate. The basal plate bears numerous tiny, cylindrical and sharply pointed teeth on the apex of the outer surface. This type agrees morphologically with the tooth plates that in Recent Amia calva occupy the posterior border of the branchial arches (Fig. 10H). The second type of branchial tooth plates found in USNM 279856 (Fig. 10C-G) has developed a pedicle instead of a basal plate. The pedicle is expanded at its distal end to accommodate some teeth that form an obtuse angle with the pedicle and in this way give the tooth plate a rake-like appearance. The number of teeth varies in this type but does not seem to exceed ten. The teeth themselves are more or less compressed laterally and sickle-shaped at the apex.

\section{Axial Skeleton}

Some isolated and detached fragmentary ossifications that were found on the part behind the neurocranium seem to represent remains of the axial skeleton. I was, however, unable to identify these remains with certainty. Some other remains of the axial skel- eton are visible in the tail region of USNM 279856. They will be dealt with together with the skeleton of the caudal fin (see below). A brief account of the axial skeleton of Lepidotes mantelli was given by Woodward (1916).

\section{Shoulder Girdle and Pectoral Fins Endoskeletal Shoulder Girdle}

Scapulocoracoid (Fig. 2, Sco)-Immediately behind the lower portion of the left cleithrum lies a peculiar endochondral ossification in the part of USNM 279856. The bone is stout, asymmetrical, and folded. The margin of its larger wing is interrupted by a deep incision. The smaller wing bears a prominent and massive ridge on its visible surface. Morphologically this bone does not agree with any of the known endochondral ossifications of the neurocranium and the visceral arches of Lepidotes. Its position in the fossil close to one of the cleithra suggests that it represents the endochondral shoulder girdle (or at least a part thereof). In Amia the endoskeletal shoulder girdle consists of a single piece of cartilage that does not allow discrimination of a separate scapula and coracoid (Jessen, 1972). (For discussion of the terms "scapula" and "coracoid" and their use in actinopterygians see also Jessen, 1972.) From studies of primitive, fossil actinopterygians such as Moythomasia, Palaeoniscum, Pteronisculus, Birgeria, etc. it is known that their primary shoulder girdle ossified as a single piece (Jessen, 1972). I therefore interpret the endochondral ossification behind the left cleithrum in USNM 279856 as a scapulocoracoid.

The endochondral shoulder girdle is poorly known in Lepidotes. The holotype of L. mantelli shows a bone below the cleithrum identified by Woodward (1916: pl. 8, fig. 1) as a coracoid. Rayner (1948) later considered the same bone to be a scapula. From Woodward's figure I can, however, recognize only little resemblance between that bone and the ossification Sco in USNM 279856. It remains uncertain whether the two bones are homologous or represent different ossifications.

\section{Exoskeletal Shoulder Girdle}

Posttemporal (Fig. 2, Pt)-Only the right posttemporal can be observed. It is partly covered by the supracleithrum. The bone has been dislocated and reversed after death and now displays its medial side. The posttemporal is elongated in anteroposterior direction and of roughly triangular shape. Its medial surface is concave, its lateral surface convex. At the posterior border a long and slender ventral process arises from the medial face (Fig. 2, v. proc. Pt). The cephalic portion of the lateral line emerges from the bone through an opening at the base of the ventral process to pass into the supracleithrum (Fig. 2, cll). A pit on the medial side, posteromedial to the ventral process, functioned as an articular surface for the supracleithrum.

Morphologically the posttemporal agrees almost perfectly with the posttemporal of Amia calva. Besides the triangular shape the posttemporal of Amia has a 
long and slender ventral process on its medial surface originating near the posterior border of the bone. In Amia, as well, the canal for the cephalic portion of the lateral line opens at the base of the ventral process. However, in Amia the ventral process is attached to the intercalar. In Lepidotes toombsi the ventral process of the posttemporal articulates with a little process on the ridge separating the posterior and lateral surfaces of the exoccipital. This process on the exoccipital of $L$. toombsi (which seems to be lacking in USNM 279856, see above) was therefore regarded as homologous with the intercalar in holosteans and teleosteans (Patterson, 1975).

Supracleithrum (Fig. 2, Scl)-A large portion of this bone is covered by the operculum in USNM 279856. The visible part reveals that the supracleithrum has a straight anterior and a convex posterior border. The bone does not bear any ornamentation on its outer surface. The cephalic portion of the lateral line has entered the supracleithrum at its anterodorsal corner and has presumably left it at about the middle of its posterior border (Fig. 2, cll). The canal for the lateral line opens through pores on the outer side of the bone.

Cleithrum (Fig. 2, Cl)-Both left and right cleithra are preserved in USNM 279856. The cleithrum is a long, arched ossification, narrow in its dorsal one fourth but much expanded in its ventral three fourths. The dorsal extremity of the cleithrum is developed as a strong process (Fig. 2, d. proc. $\mathrm{Cl}$ ) by which the bone must have articulated with the supracleithrum. In the expanded lower three fourths the anterior portion of the bone is folded inward producing posteriorly a laterally oriented outer surface and anteriorly a mediolaterally oriented outer surface. Along the ridge separating the lateral and the mediolateral surface the middle part of the cleithrum bears on its external side eight to ten longitudinal, parallel bands of very small denticles. These denticles are multicuspid and have their cusps directed posteriorly. Cleithral denticles of the same type also occur in the Recent Amia calva and have previously been reported from other Mesozoic actinopterygians including Lepidotes (Patterson, 1977; Jarvik, 1980). In Amia, as well, the cleithral denticles are arranged in long, narrow bands. However, in Amia these dental bands wind randomly over a part of the external face of the cleithrum and do not show any specific pattern (pers. obs.).

Clavicle (Fig. 2, Cla)-A long, narrow, and thin strip of bone covers the anteroventral part of the outer face of the right cleithrum. Its ventral border is convex and its dorsal border is concave. The bone is devoid of ornamentation or denticles on its external surface. It is possible that originally this bone had a more forward position in the shoulder girdle of USNM 279856, so that only the hinder part of it covered the anteroventral portion of the cleithrum. Because of the position of the bone lateral (and possibly anterior) to the lower part of the cleithrum I consider it to be homologous with the clavicle of primitive actinopterygians (Jarvik, 1944). The presence of a clavicle in Lepidotes has previously been mentioned only by Patterson (1977) who, unfortunately, did not record his observations in detail.

Amia does not possess a clavicle. Instead, Amia has two pairs of so-called "serrated appendages" (or flagella) of which the posterior one has been homologized with the clavicle (Liem and Woods, 1973).

Postcleithra (Fig. 2, Pcl)-There is a series of platelike postcleithra in Lepidotes containing a varying number of elements (e.g., three in $L$. minor, four in $L$. mantelli; Woodward, 1916). At least one of these elements is present in the part of USNM 279856. The bone in question is a thin plate lying behind the cleithrum. Its anterodorsal margin is covered by the fragment of the suboperculum above. The plate is teardrop shaped with the expanded part below. The entire posterior border of the bone is serrated and its outer surface shows traces of tuberculations ventrally.

The number of postcleithral plates remains unknown in USNM 279856. The plate described above was probably from the middle of a series of (at least three) postcleithral elements because in other species of Lepidotes the uppermost postcleithrum is known to be much more elongated dorsoventrally and to be in contact with the supracleithrum above (Woodward, 1916; Wenz, 1967).

\section{Pectoral Fin}

Little remains of the pectoral fin skeleton in USNM 279856. The remains comprise four fragments of long and slender (proximal) radials that have expanded proximal and distal extremities (Fig. 2, Ra). Below the radials lie remains of lepidotrichia (Fig. 2, Le). These represent only the unsegmented basal parts of some fin rays that have lost their segmented distal portion during fossilization. The proximal extremity of the fin rays is differentiated into two small and inconspicuous processes for the insertion of pectoral fin muscles. There is no ganoin cover on the lepidotrichia. The exact number of radials and lepidotrichia remains unknown.

Fulcra seem to be lacking in the pectoral fin. Instead, the leading edge of the pectoral fin was stiffened and protected by a long and strong spine, which bears a rudimentary, narrow strip of ganoin on its proximal part (Fig. 2, Sp). This spine presumably represents a modified pair of lepidotrichia.

\section{Pelvic Girdle and Fins}

The pelvic girdle of USNM 279856 consists of a pair of large, elongated, and thin plates that are well ossified (Fig. 11, pP). The plates are triangular with the anterior part expanded. The posterior extremity of each plate is developed into a condyle for the articulation of the pelvic fin.

The pelvic fin is formed by five pairs of lepidotrichia; only four of them are visible in Figure 11 (Le). The lepidotrichia of the pelvic fins strongly resemble those of the pectoral fins in having a long unsegmented basal portion and two stout processes at their proximal extremity. Apparently, the pelvic fins were also not fringed 
with fulcra. If there were endoskeletal components present in the pelvic fin skeleton these must have been formed entirely by cartilage and are not preserved. In position the pelvic fins are closer to the anal fin than to the pectoral fins (Fig. 1).

\section{Unpaired Fins}

The dorsal fin has almost completely disintegrated (Fig. 1). Most of its lepidotrichia are scattered above the caudal peduncle. The dorsal fin inserts a little behind the pelvic fins, and its anterior edge is fringed with fulcra.

The anal fin is placed slightly in front of the caudal peduncle (Fig. 1). All of its lepidotrichia have lost their segmented part. The endoskeletal components are covered by scales and are not visible. The front edge of the anal fin is also protected by fulcra.

The exoskeleton of the caudal fin has also completely disintegrated. Some remains of the endoskeleton, however, are preserved and visible. The caudal fin is supported by a series of hypurals. In USNM 279856 hypurals 1 to 7 can be observed (Fig. 12, H 1-7). All of these consist of a laterally broadened, plate-like proximal part (=basal plate), which is slightly arched transversely and which once rested against the ventral side of the notochord. The basal plate is fully ossified and represents the arcocentral component of the hypurals. From the basal plate a stout, rod-like process projects posteroventrad. In hypural 3 this ventral process is partly broken and shows that it was mainly formed by cartilage that was only superficially lined by a thin layer of perichondral bone. In hypurals 1 and 2 the ventral process is compressed laterally. Posteriorly the hypurals diminish in size gradually. Their exact number in the caudal fin skeleton of USNM 279856 remains unknown because the posterior part of the hypural series is still enclosed in the counterpart. In Lepidotes elvensis, Wenz (1967) has counted 17 hypurals.

Posteriorly a series of ossified radials joins the hypurals. Two of these radial elements are still in their original position in the caudal fin skeleton (Fig. 12, $\mathrm{Ra}$; a third radial is detached and therefore not shown in Fig. 12). The upper one is nearly complete and reveals the unusual size and shape of the caudal fin radials in USNM 279856. The main part of the radial is a rounded and columnar piece of bone. It is only a little shorter than the ventral processes of the neighboring hypurals and equals those in diameter. Its proximal extremity is bifurcate showing two branches or processes of different length. The lower and longer of these branches is about as long as the rest of the radial and extends along and articulates with the ventral processes of the three hypurals in front of it. The two other caudal fin radials preserved display the same morphology. Ossified caudal fin radials of this size and shape are unknown in any other actinopterygian species. Unfortunately, the exact number of radials present in the caudal fin skeleton of USNM 279856 remains obscure. Because most of the radial elements were pre-
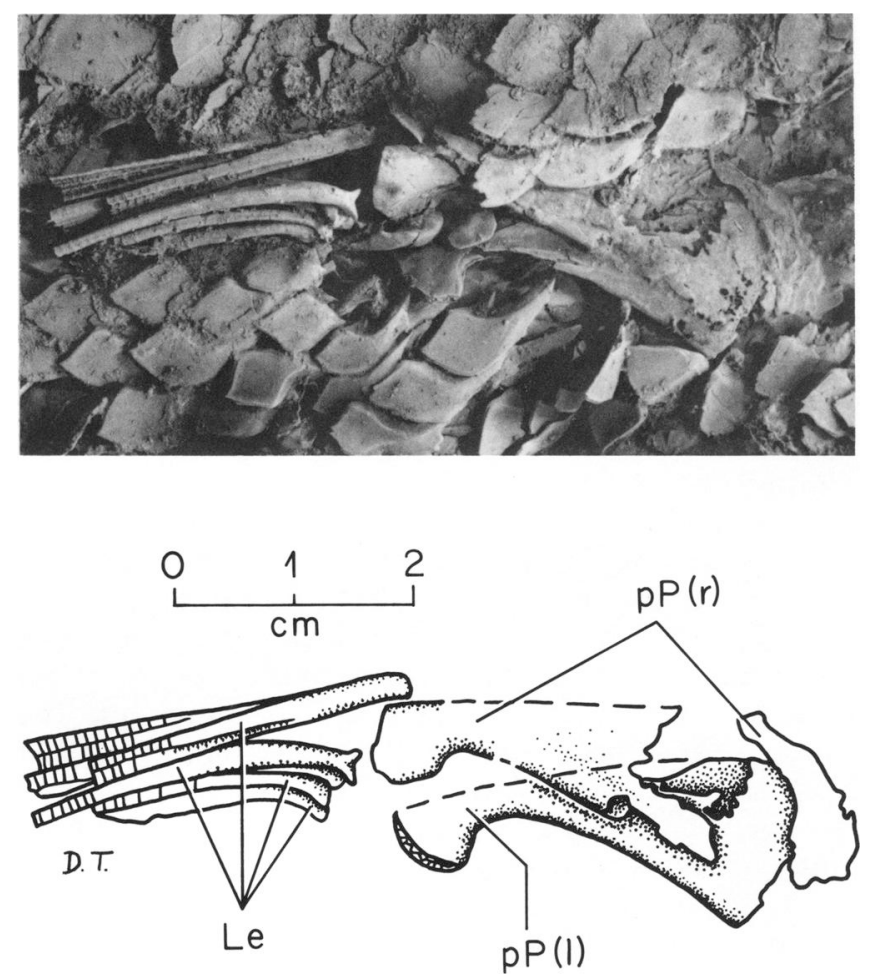

FIGURE 11. Lepidotes gloriae, sp. nov. (holotype, USNM 279856, part). Pelvic girdle. Lateral view.

sumably articulating with several hypurals, the number of radials should be much smaller than the number of hypurals.

Anterior to hypural 1 the haemal arches (and the proximal parts of the haemal spines) of the first six preural vertebrae are visible (Fig. 12, Har (Pu 1-6)). In the most posterior preural vertebra $(\mathrm{Pu} 1)$ the right haemal arch is broken off and reveals the canal for the caudal artery and vein, which is asymmetrical in USNM 279856 and posteriorly opens to the right side. The haemal spines of at least the first preural vertebra must have taken part in the caudal fin support.

Above the level of the notochord some neural arches of the preural vertebrae also become visible in the tail of USNM 279856 (Fig. 12, Nar). These cannot be assigned to specific preural vertebrae with certainty. They are smaller and less expanded than the corresponding haemal arches and their spines seem to be shorter and more delicate than the haemal spines.

Behind the neural arches and above the hypurals lies a small, rod-like piece of bone among some disarranged scales (Fig. 12, ?E). This bone may represent a fragment of an epural.

The upper lobe of the caudal fin was fringed with fulcra.

\section{Scales}

In the trunk region of USNM 279856 most scales are more or less damaged and covered by a thin layer 


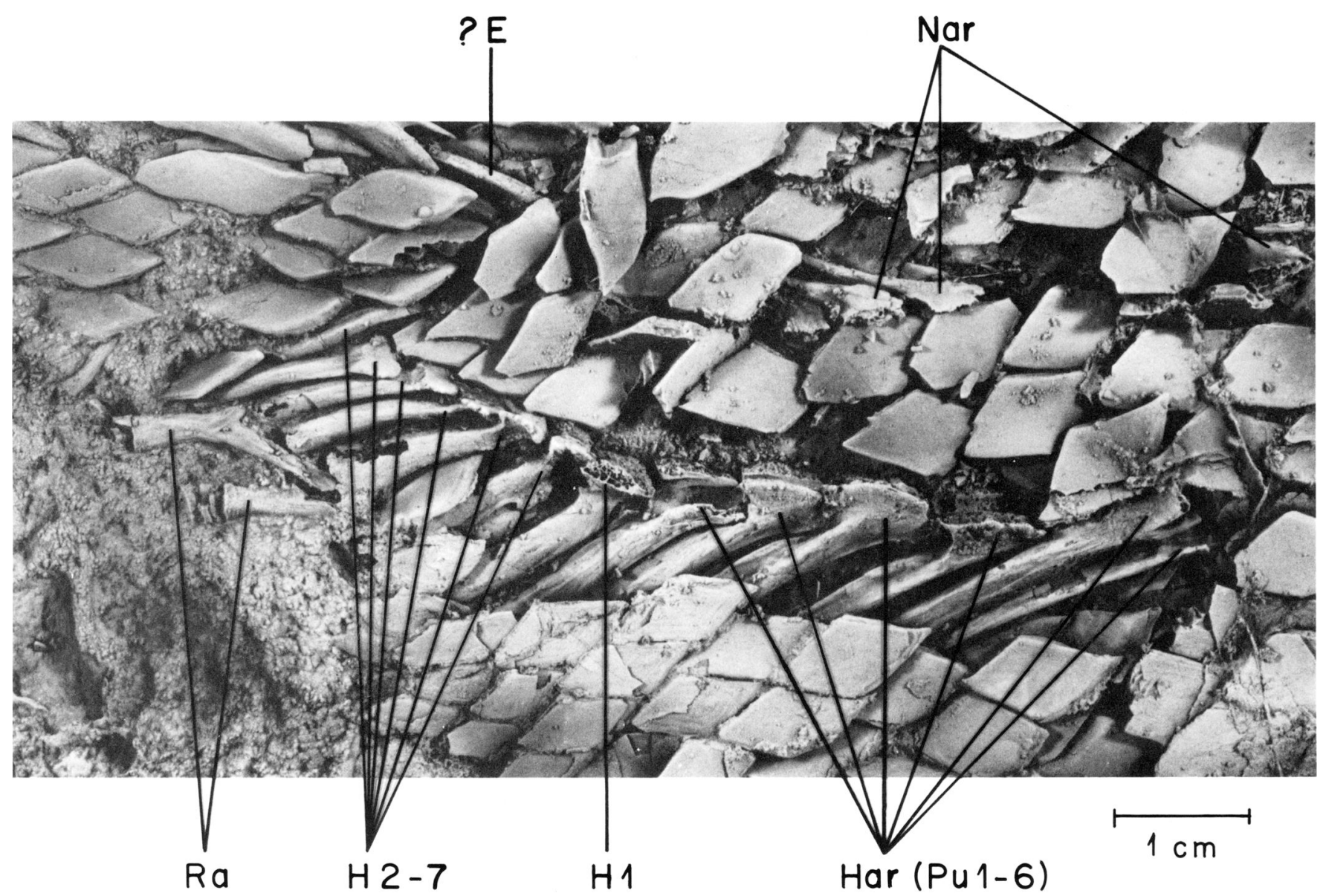

FIGURE 12. Lepidotes gloriae, sp. nov. (holotype, USNM 279856, part). Caudal fin skeleton. Lateral view.

of pyrite. Nevertheless, it can be discerned that all scales bear a superficial cover of ganoin and lack ornamentation. Some better preserved scales behind the opercular apparatus show that the flank scales of the trunk are almost twice as high as long (Fig. 13). The posterior border of these scales is serrated over its entire length. Towards the dorsal and ventral midline of the body and in the abdominal region the serration of the scales gradually disappears and is confined to the ventral part of the posterior border. In the immediate vicinity of the dorsal and ventral midline and on the posterior portion of the caudal peduncle the serration is absent, and the posterior border of the scales is smooth. The dorsal ridge scales between the skull and the origin of the dorsal fin are acuminate posteriorly but lack a posterior spine as present in Semionotus (McCune, 1986).

\section{REMARKS ON THE CRANIAL SENSORY LINE SYSTEM}

The cranial sensory line system of USNM 279856 shows some remarkable features. These are:

1) Enclosure within the Parietals of the Supratemporal Commissure-In USNM 279856 a continuous transverse canal runs along the posterior edge of the parietals (Figs. 6, 7; st). Laterally the canal starts at the parietal/extrascapular boundary and is therefore considered as the median part of the supratemporal commissure.

In actinopterygians the supratemporal commissure is normally found on the extrascapular series of bones exclusively. Among fossil actinopterygians only Tetragonolepis semicincta is known to have the median part of the supratemporal commissure lodged in the parietals (Thies, in prep.). In Tetragonolepis the extrascapular series seems to be reduced. There is only one pair of lateral extrascapulars in this fish. These are separated medially by the posteriorly extended parietals that border posteromedially on the scales of the trunk. In USNM 279856 the number and arrangement of extrascapular bones is unknown. However, the median part of the supratemporal commissure is enclosed in the parietals indicating that USNM 279856 may also have lacked median extrascapulars (like Lepidotes elvensis and L. lennieri, in which, however, the course of the supratemporal commissure is still unknown; Wenz, 1967).

In the living teleost Abramis brama the parietals are also pierced by a canal for the supratemporal com- 
missure (Holmgren and Stensiö, 1936). Holmgren and Stensiö claimed the presence of a supratemporal canal in the parietals of this fish was evidence for the fusion of an extrascapular element with the parietal. It is, however, also possible that the course of the supratemporal canal through the parietals results from complete reduction of median extrascapular elements. Unfortunately, detailed embryological and ontogenetical data concerning the development of the dermal skull roof of Abramis brama, which would help to answer this question, are still missing.

2) Presence of a Medioanteriorly Directed Branch of the Infraorbital Canal Behind the Orbit - In USNM 279856 the infraorbital canal sends a medioanteriorly directed branch from the dermopterotic into the frontal (Fig. 8, mbioc). Unfortunately, it cannot be determined if this branch anastomoses with the supraorbital canal in the frontal.

Among fossil actinopterygians a medioanteriorly directed branch of the infraorbital canal is otherwise known only in Tetragonolepis (Thies, in prep.). In Tetragonolepis this branch also originates in the dermopterotic and passes into the frontal where it terminates above the middle of the orbit. Its course in the frontal of Tetragonolepis is lateral and parallel to the supraorbital canal. It is unknown if there is an anastomosis between this branch of the infraorbital canal and the supraorbital canal in Tetragonolepis.

Three other species of Lepidotes show similar conditions in regard to the development of the supraorbital and infraorbital canals. In L. laevis the supraorbital canal has a posterolaterally directed branch. This branch leaves the supraorbital canal in the frontal in the immediate vicinity of the frontal/dermopterotic boundary. It reaches back far into the dermopterotic (="supra-temporal") but does not anastomose with the infraorbital canal (Saint-Seine, 1949). In L. elvensis and $L$. notopterus the infraorbital canal has a medioposteriorly directed branch that detaches from the canal in the anteriormost part of the dermopterotic. In both fishes this branch runs back to the medial edge of the dermopterotic opposite the anterolateral corner of the parietal. It is unknown if this branch of the infraorbital canal in L. elvensis and L. notopterus continues posteriorly into the parietal (Dechaseaux, 1943; Saint-Seine, 1949).

The course of the supraorbital canal varies widely in actinopterygians. In palaeoniscoids the supraorbital canal generally extends from the snout back into the parietal. There is no postorbital connection between the supraorbital and infraorbital canals (Moy-Thomas and Miles, 1971). In Amia the supraorbital canal terminates posteriorly near the posterior margin of the frontal. There is a canal connecting the infraorbital and supraorbital canal that extends from the dermopterotic into the frontal (Allis, 1889; Arratia, pers. comm.). In many (higher) teleosteans the supraorbital canal does not extend far back in the frontal but joins the infraorbital canal behind the orbit. With the supraorbital canal extending into the parietal posteriorly and the in-

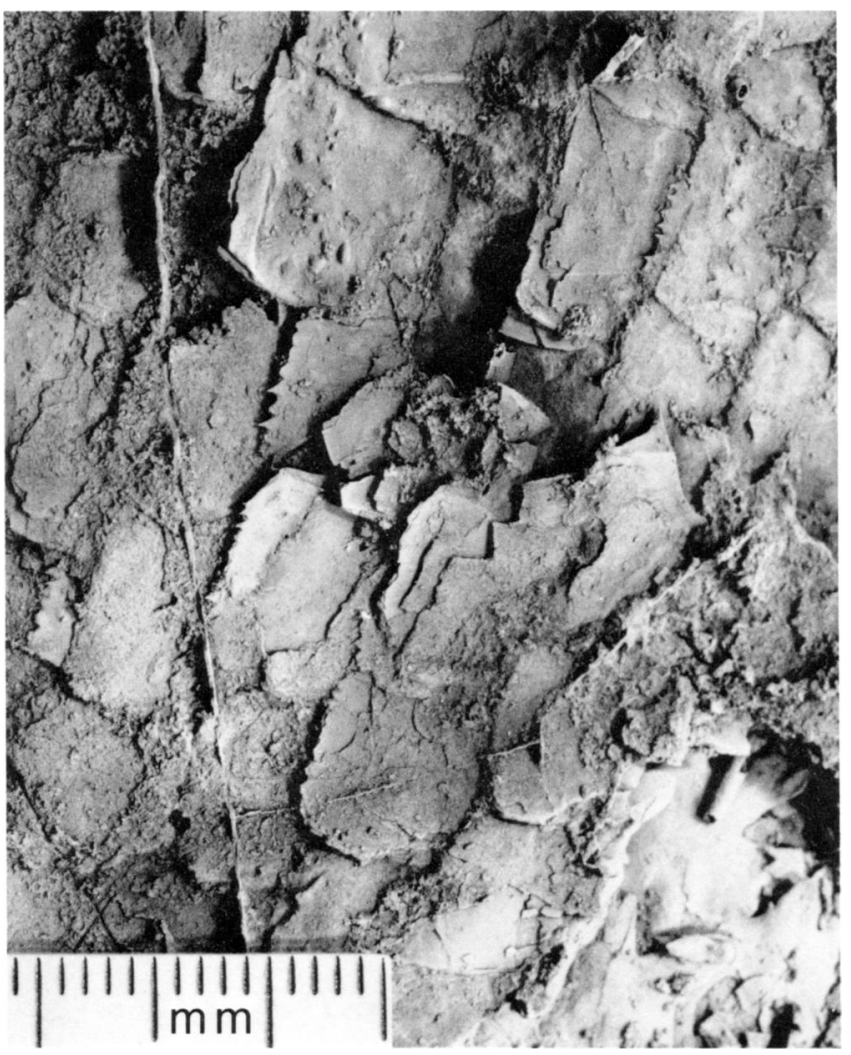

FIGURE 13. Lepidotes gloriae, sp. nov. (holotype, USNM 279856 , part). Squamation of the trunk behind the opercular apparatus.

fraorbital canal having a medioanterior branch behind the orbit USNM 279856 takes an intermediate position between the palaeoniscids and Amia in regard to the development of the supraorbital and infraorbital canals.

3) Ventral Part of the Median Pit Line of the Skull Roof Replaced by a Short Canal in the DermopteroticThere are no traces of pit lines on the parietals of USNM 279856. The posterior part of the dermopterotic is traversed dorsoventrally by a short, superficial canal, which by its position and orientation can be homologized with the ventral part of the median pit line of the skull roof (Fig. $8, \mathrm{mpl}$ ).

Published information on the cranial sensory canal and pit line system of Lepidotes is surprisingly little and widely dispersed in the literature. $L$. semiserratus has all three pit lines of the skull roof (i.e., anterior, median, and posterior pit line) with the anterior pit line extending from the parietal onto the frontal and the median pit line extending from the parietal onto the dermopterotic (Westoll, 1937). In L. laevis only the median pit line of the skull roof is present. It also extends over the parietal and the dermopterotic (SaintSeine, 1949). In L. minor and L. mantelli, as well, only the median pit line of the skull roof seems to be present but Woodward's (1916) descriptions are not clear on 
this point. In no case has it been reported that one of the cranial pit lines of Lepidotes, or a part of it, has been replaced by a canal completely enclosed by bone.

Among other fossil actinopterygians the replacement of one or more cranial pit lines by canals or fragments of canals has been observed repeatedly, e.g., in Cheirolepis canadensis, in which the median and posterior pit lines of the skull roof are represented by canals embedded in the parietal (Lehman, 1947). In the semionotiform genus Dapedium the anterior pit line of the skull roof as well as the horizontal and vertical pit lines of the cheek can be replaced by canals (Wenz, 1967; Thies, 1988). The functional significance of this phenomenon is still obscure.

4) Presence of an Oral Canal in the Anterior Portion of the Dentalosplenial - The dentalosplenial of USNM 279856 has enclosed in its anterior portion two longitudinal canals situated one above the other. The ventral one represents the mandibular canal (Figs. 2, 5; $\mathrm{mc}$ ) whereas the dorsal one is identified here as the oral canal (Figs. 2, 5; oc). Both canals open separately on the lateral side of the dentalosplenial by a separate row of pores each.

The general plan of the sensory lines on the head of Recent fishes and amphibians includes six lines, two of which are located on the lower jaw; the oral line dorsally and the mandibular line ventrally (Stensiö, 1947). In actinopterygians the mandibular line is lodged in a canal running through the dermal bones of the lateral side of the lower jaw (=mandibular canal). Relatively little is known about the oral line. In many Recent and fossil actinopterygians there is a mandibular pit line above the mandibular canal on the posterior portion of the lower jaw. Additionally, in some fossil actinopterygians there is a short dentary (=oral) pit line, which is situated just above the anterior extremity of the mandibular canal on the anterior part of the lower jar near the symphysis, e.g., Mimia toombsi and Haplolepis ovoidea (Westoll, 1944; Gardiner, 1984). In Brachydegma caelatum this pit line extends far back on the dentary (Dunkle, 1939). Based on embryological data from Recent fishes and amphibians Stensiö (1947) has interpreted the mandibular and dentary pit lines of fossil actinopterygians as marks left by the posterior and anterior portions of the oral sensory line, respectively. In some osteolepiforms, porolepiforms, and dipnoans the posterior portion of the oral line lies deep within the bone and is enclosed in a canal (Stensiö, 1947; Jarvik, 1972; Gardiner, 1984); in actinopterygians this sensory line seems to be much more superficial. A canal or a fragment of a canal in the lower jaw for the oral sensory line has never been reported from any living or fossil actinopterygian. However, the position of the upper canal in the dentalosplenial of USNM 279856, dorsal to the anterior end of the mandibular canal, leaves little doubt that it represents the homologue of the dentary pit line of other fossil actinopterygians and must once have lodged the anterior portion of the oral sensory line.

There are at least two more species of Lepidotes known to have a double row of sensory canal pores on the anterior part of the lower jaw: L. elvensis from the Early Jurassic of France, Germany, and England (Dechaseaux, 1943; Wenz, 1967) and L. minor from the Wealden (Early Cretaceous) of North-West Germany (which is possibly not identical with $L$. minor from the Purbeckian (Early Cretaceous) of England; Branco, 1887). Wenz (1967) concluded that this phenomenon represents only a "dédoublement des pores de la section antérieure du canal mandibulaire." The conditions found in USNM 279856, however, strongly suggest the presence of a distinct oral sensory canal dorsal to the anterior part of the mandibular canal in $\mathrm{L}$. elvensis and in L. minor (from the Wealden of NorthWest Germany).

\section{DISCUSSION}

The fish from the Late Jurassic of Western Cuba agrees with four of the five diagnostic characters of Lepidotes as given above, i.e., it has a single median vomer, a dentalosplenial with a long posterior process, two pockets in the epiotic, and inconspicuous dorsal ridge scales that lack a posterior spine. Nothing can be said about the number of suborbitals because these ossifications were lost after the death of the specimen. The median vomer and the dentalosplenial having a long posterior process clearly separates the fish from Cuba from the other two fusiform semionotid genera Acentrophorus and Semionotus in which the vomer is paired and the dentalosplenial does not develop a prominent posterior process. Furthermore, the specimen differs from Semionotus by the presence of inconspicuous dorsal ridge scales. In accordance with $L$. toombsi from the European Late Jurassic the specimen from Cuba shows two pockets in the epiotic. There is therefore no doubt that the fish from the Late Jurassic of Cuba belongs to Lepidotes. The generic identification is additionally supported by the presence of two rows of sensory canal pores on the dentalosplenial, a feature that among actinopterygians is found otherwise only in L. elvensis, the type species of Lepidotes, and in $L$. minor from the Wealden of northwestern Germany.

The specific identification is, however, more problematical. Late Jurassic species of Lepidotes are numerous and comprise at least 19 taxa: Lepidotes affinis Fricke, 1875-Oxfordian/Kimmeridgian of NW Germany; Lepidotes decoratus Wagner, 1863-Tithonian of S Germany; Lepidotes intermedius Wagner, 1863Tithonian of S Germany; Lepidotes koeneni Branco, 1887-Kimmeridgian of NW Germany; Lepidotes laevigatus Sauvage, 1879-Oxfordian of France; Lepidotes laevis Agassiz, 1837-Kimmeridgian of Switzerland and SE France; Lepidotes latifrons Woodward, 1893-Oxfordian of England; Lepidotes leedsi Woodward, 1895-Oxfordian/Kimmeridgian of England; Lepidotes lennieri Sauvage, 1893-Kimmeridgian of France; Lepidotes macrocheirus Egerton, 1845-Oxfordian of England; Lepidotes maximus Wagner, 
1863-Late Jurassic/Early Cretaceous of Germany, France, England, Switzerland, Austria, and Italy; $L e$ pidotes minor Agassiz, 1837-Purbeckian of England; Lepidotes notopterus Agassiz, 1837-Kimmeridgian/ Tithonian of S Germany and SE France; Lepidotes oblongus Agassiz, 1837-Tithonian of S Germany; Lepidotes palliatus Agassiz, 1837-Oxfordian/Kimmeridgian of Germany, France, and England; Lepidotes pusillus Bocchino, 1973-?Late Jurassic of Argentina; Lepidotes subovatus (Muenster, 1842)Tithonian of S Germany; Lepidotes toombsi Jain and Robinson, 1963-Kimmeridgian/Tithonian of England; and Lepidotes unguiculatus Agassiz, 1837-Tithonian of S Germany.

The majority of the above listed species, i.e., L. macrocheirus, $L$. laevigatus, $L$. latifrons, $L$. palliatus, $L$. leedsi, L. laevis, L. koeneni, L. lennieri, L. toombsi, $L$. decoratus, $L$. intermedius, and $L$. minor, differs from the Lepidotes from the Late Jurassic of Western Cuba in having the external cranial bones ornamented to a varying extent by ganoin tubercles or rugae (Agassiz, 1837; Wagner, 1863; Branco, 1887; Woodward, 1895; Saint-Seine, 1949; Jain and Robinson, 1963; Wenz, 1967). Additionally, unlike the specimen from Cuba the dentition is moderately or strongly tritoral in $L$. macrocheirus, L. latifrons, $L$. palliatus, $L$. leedsi, $L$. laevis, $L$. lennieri, L. toombsi, $L$. decoratus, and $L$. minor. (In L. laevigatus, L. koeneni, and L. intermedius the dentition is unknown because the specimens are missing the anterior part of the head.) Only L. notopterus, $L$. unguiculatus, and $L$. pusillus possess, like USNM 279856, smooth or nearly smooth external cranial bones. However, the teeth are tritoral in $L$. notopterus and L. unguiculatus. Besides, in both species the posterior border of the scales is straight (Agassiz, 1837 ) and the paired fins are fringed with fulcra (Wagner, 1863; Woodward, 1895) whereas in the Lepidotes from Cuba the hinder border of the scales is serrated and the paired fins lack fulcra. In $L$. pusillus the external bones of the head are of different dimensions and shape (Bocchino, 1973).

L. maximus is a giant species with a body length of about $2 \mathrm{~m}$ and a strongly developed tritoral dentition (Jain, 1985). The Lepidotes from Cuba is much smaller and its dentition is non-tritoral.

L. oblongus is based on several fragments of a large fish. The head is missing and the species is therefore insufficiently defined. Wagner (1863) stated that the scales of $L$. oblongus are longer than high. In USNM 279856 the scales (of the trunk) are higher than long.

Even less is known about $L$. affinis. Fricke (1875) founded this species on some jaw and palatal roof fragments that differ from USNM 279856 in bearing a tritoral dentition.

The systematic position of $L$. subovatus is unclear. Münster (1842), Agassiz (1844), and Wagner (1863) put this species into its own genus, Scrobodus, whereas Woodward (1895) regarded it as congeneric with $\mathrm{Le}$ pidotes. According to Wagner (1863) L. subovatus might represent a dwarf species of Lepidotes. It differs from all other species of Lepidotes, including the specimen from Cuba, by its specialized dental morphology, which resembles that of Gyrodus.

Finally, in none of the above listed Late Jurassic species of Lepidotes does the pectoral fin have a spine. Possession of a spine is a prominent feature of the Cuban specimen.

The discussion above demonstrates that the Lepidotes from the Late Jurassic of Western Cuba does not agree at the species level with known Late Jurassic species of Lepidotes and I therefore consider it to be a new species.

\section{ACKNOWLEDGMENTS}

This study was supported by a grant from the "Wissenschaftsausschuß der NATO," which was awarded to me by the "Deutscher Akademischer Austauschdienst." The USNM provided the Lepidotes material from the Late Jurassic of Western Cuba. Drs. P. Humphrey and H.-P. Schultze allowed access to all necessary facilities at the Museum of Natural History (KU). Drs. G. Arratia and H.-P. Schultze spent much time with me discussing skeletal anatomy of actinopterygians. O. Bonner, Dr. J. Chorn, M. Gottfried, and J. McAllister (all Museum of Natural History, KU) provided technical assistance. Dr. J. Chorn improved the English. To all these institutions and individuals I express my sincere thanks.

\section{LITERATURE CITED}

Agassiz, L. J. R. 1832. Untersuchungen über die fossilen Fische der Lias-Formation. Neues Jahrbuch für Mineralogie, Geognosie, Geologie und Petrefaktenkunde 3: 139-149.

1833-1844. Recherches sur les poissons fossiles, Vols. I-V. Petitpierre, Neuchatel.

Allis, E. P. 1889. The anatomy and development of the lateral line system in Amia calva. Journal of Morphology 2:463-566.

1897. The cranial muscles and cranial and first spinal nerves in Amia calva. Journal of Morphology 12: 487-808.

1898. On the morphology of certain of the bones of the cheek and snout of Amia calva. Journal of Morphology 14:425-466.

Arratia, G., and H.-P. Schultze. 1985. Late Jurassic teleosts (Actinopterygii, Pisces) from northern Chile and Cuba. Palaeontographica A 189:29-61.

Bjerring, H. C. 1984. The term "Fossa Bridgei" and five endocranial fossae in teleostome fishes. Zoologica Scripta $13: 231-238$.

Blainville, H. D. 1818. Poissons fossiles; in Nouveau Dictionnaire d'Histoire Naturelle, XXVII. Paris.

Bocchino, A. 1973. Semionotidae (Pisces, Holostei, Semionotiformes) de la Formacion Lagarcito (Jurasico superior?), San Luis, Argentina. Ameghiniana 10:254-268.

Branco, W. 1887. Beiträge zur Kenntniss der Gattung Lepidotus. Abhandlungen zur geologischen Specialkarte von Preussen and den Thüringischen Staaten 7:317-407.

Dechaseaux, C. 1943. Contribution à l'étude du genre Lepidotus. Annales de Paléontologie 30:3-13. 
Dunkle, D. H. 1939. A new paleoniscid fish from the Texas Permian. American Journal of Science 237:262-274.

Egerton, P. G. 1845. On some new species of fossil fish, from the Oxford Clay at Christian Malford. The Quarterly Journal of the Geological Society of London 1:229232.

Fricke, K. 1875. Die fossilen Fische aus den oberen Juraschichten von Hannover. Palaeontographica 22:349398.

Gardiner, B. G. 1960. A revision of certain actinopterygian and coelacanth fishes, chiefly from the Lower Lias. Bulletin, British Museum (Natural History), Geology, 4: 241-384.

1984. The relationships of the palaeoniscid fishes, a review based on new specimens of Mimia and Moythomasia from the Upper Devonian of Western Australia. Bulletin, British Museum (Natural History), Geology, 37:173-428.

Gill, E. L. 1923. The Permian fishes of the genus Acentrophorus. Proceedings, Zoological Society of London 1923: $19-40$.

Gregory, W. K. 1923. A Jurassic fish fauna from Western Cuba, with an arrangement of the families of the holostean ganoid fishes. Bulletin, American Museum of Natural History 48:223-242.

Herrera, N. M. 1961. Contributión à la estratigrafia de la provincia de Pinar del Rio. Revista de la Sociedad $\mathrm{Cu}-$ bana de Ingenieros 61:1-24.

Holmgren, N., and E. A. Stensiö. 1936. Kranium und Visceralskelett der Akranier, Cyclostomen und Fische; pp. 233-500 in L. Bolk, E. Göppert, E. Kallius, and W. Lubosch (eds.), Handbuch der vergleichenden Anatomie der Wirbeltiere, Vol. 4. Urban und Schwarzenberg, Berlin, Wien.

Jain, S. L. 1983. A review of the genus Lepidotes (Actinopterygii: Semionotiformes) with special reference to the species from the Kota Formation (Lower Jurassic), India. Journal, Palaeontological Society of India 28:742.

1985. Some new observations on Lepidotes maximus (Holostei: Semionotiformes) from the German Upper Jurassic. Journal, Palaeontological Society of India 30:18-25.

and P. L. Robinson. 1963. Some new specimens of the fossil fish Lepidotes from the English Upper Jurassic. Proceedings, Zoological Society of London 141:119-135.

Jarvik, E. 1944. On the exoskeletal shoulder girdle of teleostomian fishes with special reference to Eusthenopteron foordi Whiteaves. Kunglingen Svenska VetenskapsAkademiens Handlingar, 3. Serien, 21:1-32.

- 1972. Middle and Upper Devonian Porolepiformes from East Greenland with special reference to Glyptolepis groenlandica $\mathrm{n}$. sp. Meddelelser om Grønland 187: 1-307.

1980. Basic Structure and Evolution of Vertebrates, Vol. 1. Academic Press, London, 575 pp.

Jessen, H. 1972. Schultergürtel und Pectoralflosse bei Actinopterygiern. Fossils and Strata 1:1-101.

Larsonneur, C. 1964. Semionotus normanniae du Trias supérieur de Basse-Normandie. Annales de Paléontologie 50:103-117.

Lehman, J.-P. 1947. Description de quelques exemplaires de Cheirolepis canadensis (Whiteaves). Kunglingen Svenska VetenskapsAkademiens Handlingar, 3. Serien, $24: 1-40$
1966. Actinopterygii; pp. 1-242 in J. Piveteau (ed.), Traité de Paléontologie, IV(3). Masson, Paris.

Liem, K. F., and L. P. Woods. 1973. A probable homologue of the clavicle in the holostean fish Amia calva. Journal of Zoology 170:521-531.

McCune, A. R. 1986. A revision of Semionotus (Pisces: Semionotidae) from the Triassic and Jurassic of Europe. Palaeontology 29:213-233.

1987. Toward the phylogeny of a fossil species flock: semionotid fishes from a lake deposit in the Early Jurassic Towaco Formation, Newark Basin. Bulletin, Yale University Peabody Museum of Natural History 43:1108.

Moy-Thomas, J. A., and R. S. Miles. 1971. Palaeozoic Fishes. Chapman and Hall, London, 259 pp.

Münster, G. Graf zu. 1842. Briefliche Mitteilung. Neues Jahrbuch für Mineralogie, Geognosie, Geologie und Petrefaktenkunde 12:97-98.

Patterson, C. 1973. Interrelationships of holosteans; pp. 233-305 in P. H. Greenwood, R. S. Miles, and C. Patterson (eds.), Interrelationships of Fishes. Academic Press, London.

1975. The braincase of the pholidophorid and leptolepid fishes, with a review of the actinopterygian braincase. Philosophical Transactions, Royal Society of London, Series B, Biological Sciences, 269:275-579.

1977. Cartilage bones, dermal bones and membrane bones, or the exoskeleton versus the endoskeleton; pp. 77-121 in S. M. Andrews, R. S. Miles, and A. D. Walker (eds.), Problems in Vertebrate Evolution. Academic Press, London.

Quenstedt, F. A. 1847. Anzeige der akademischen Feier des Geburtsfestes Seiner Majestät des Königs Wilhelm von Württemberg im Namen des Rektors und des Senats der königlichen Eberhard-Karls-Universität zu Tübingen, nebst Lepidotus im Lias Epsilon Württembergs. L. F. Fues, Tübingen, $18 \mathrm{pp}$.

Rayner, D. H. 1948. The structure of certain Jurassic holostean fishes, with special reference to their neurocrania. Philosophical Transactions, Royal Society of London, Series B, Biological Sciences, 233:287-345.

- 1951. On the cranial structure of an early palaeoniscid, Kentuckia gen. nov. Transactions, Royal Society of Edinburgh 62:53-83.

Saint-Seine, P. de. 1949. Les poissons des calcaires lithographiques de Cerin (Ain). Nouvelles Archives du Muséum d'Histoire Naturelle de Lyon 2:1-357.

1950. Contribution à l'étude des Vertébrés Fossiles du Congo Belge. Annales du Musée du Congo Belge (Série in $8^{\circ}$ ), Sciences Géologiques 5:5-32.

Sauvage, M. H.-E. 1879. Étude sur les poissons et les reptiles des terrains crétacés et jurassiques supérieurs de l'Yvonne. Bulletin, Société des Sciences Historiques et Naturelles de l'Yvonne 33:20-84.

1893. Description de deux espèces nouvelles de Poissons de terrain kimméridgien du Cap de la Hève. Bulletin, Société Géologique de la Normandie 14:3-7.

Schaeffer, B. 1971. The braincase of the holostean fish Macrepistius, with comments on the neurocranial ossification in the Actinopterygii. American Museum Novitates 2459:1-34.

and D. H. Dunkle. 1950. A semionotid fish from the Chinle Formation, with consideration of its relationships. American Museum Novitates 1457:1-29.

and C. Patterson. 1984. Jurassic fishes from the 
Western United States, with comments on Jurassic fish distribution. American Museum Novitates 2796:1-86.

Silva Santos, R. da. 1953. Lepidotídeos do Cretáceo da ilha de Itaparica, Estado de Bahia. Ministério da Agricultura, Departamento Nacional da Produção Mineral, Divisão de Geologia e Mineralogia, Boletim 145:1-23.

Stensiö, E. A. 1947. The sensory lines and dermal bones of the cheek in fishes and amphibians. Kunglingen Svenska VetenskapsAkademiens Handlingar, 3. Serien, 24:1-195.

Thies, D. 1988. Dapedium pholidotum (Agassiz, 1832) (Pisces, Actinopterygii) aus dem Unter-Toarcium NWDeutschlands. Geologica et Palaeontologica 22:89-121.

Toombs, H. A., and A. E. Rixon. 1950. The use of plastics in the "Transfer Method" of preparing fossils. The Museum's Journal 50:105-107.

Wagner, A. 1863. Monographie der fossilen Fische aus den lithographischen Schiefern Bayerns. Abhandlungen der mathemat.-physikalischen Classe der königlich bayerischen Akademie der Wissenschaften 9:277-352, 613748.

Weitzel, K. 1930. Drei Riesenfische aus den Solnhofener Schiefern von Langenaltheim. Abhandlungen der Senckenbergischen Naturforschenden Gesellschaft 42:85-113.

Wenz, S. 1967. Complément à l'étude des poissons actinoptérygiens du Jurassique français. Cahiers de Paléontologie:1-276.
Westoll, T. S. 1937. On the cheek-bones in teleostome fishes. Journal of Anatomy 71:362-382.

1944. The Haplolepidae, a family of Late Carboniferous bony fishes. Bulletin, American Museum of Natural History 83:1-122.

White, T. E. 1942. A new leptolepid fish from the Jurassic of Cuba. Proceedings, New England Zoölogical Club 21: 97-100.

Wierzbowski, A. 1976. Oxfordian ammonites of the Pinar del Rio province (western Cuba); their revision and stratigraphical significance. Acta Geologica Polonica: 137-260.

Woodward, A. S. 1890. The fossil fishes of the Hawkesbury Series at Gosford. Memoir, Geological Survey of New South Wales (Palaeontological Series) 4:1-56.

- 1893. On the cranial osteology of the Mesozoic ganoid fishes, Lepidotus and Dapedius. Proceedings, Zoological Society of London 38:559-565.

1895. Catalogue of the Fossil Fishes in the British Museum (Natural History). Part III. Trustees of the British Museum, London, $544 \mathrm{pp}$.

1916-1919. The Fossil Fishes of the English Wealden and Purbeck Formations. Palaeontographical Society, volume for 1917:1-148.

Received 21 January 1988; accepted 11 August 1988. 